\title{
EVALUATION OF AIRBORNE THERMAL, MAGNETIC, AND ELECTROMAGNETIC CHARACTERIZATION TECHNOLOGIES
}
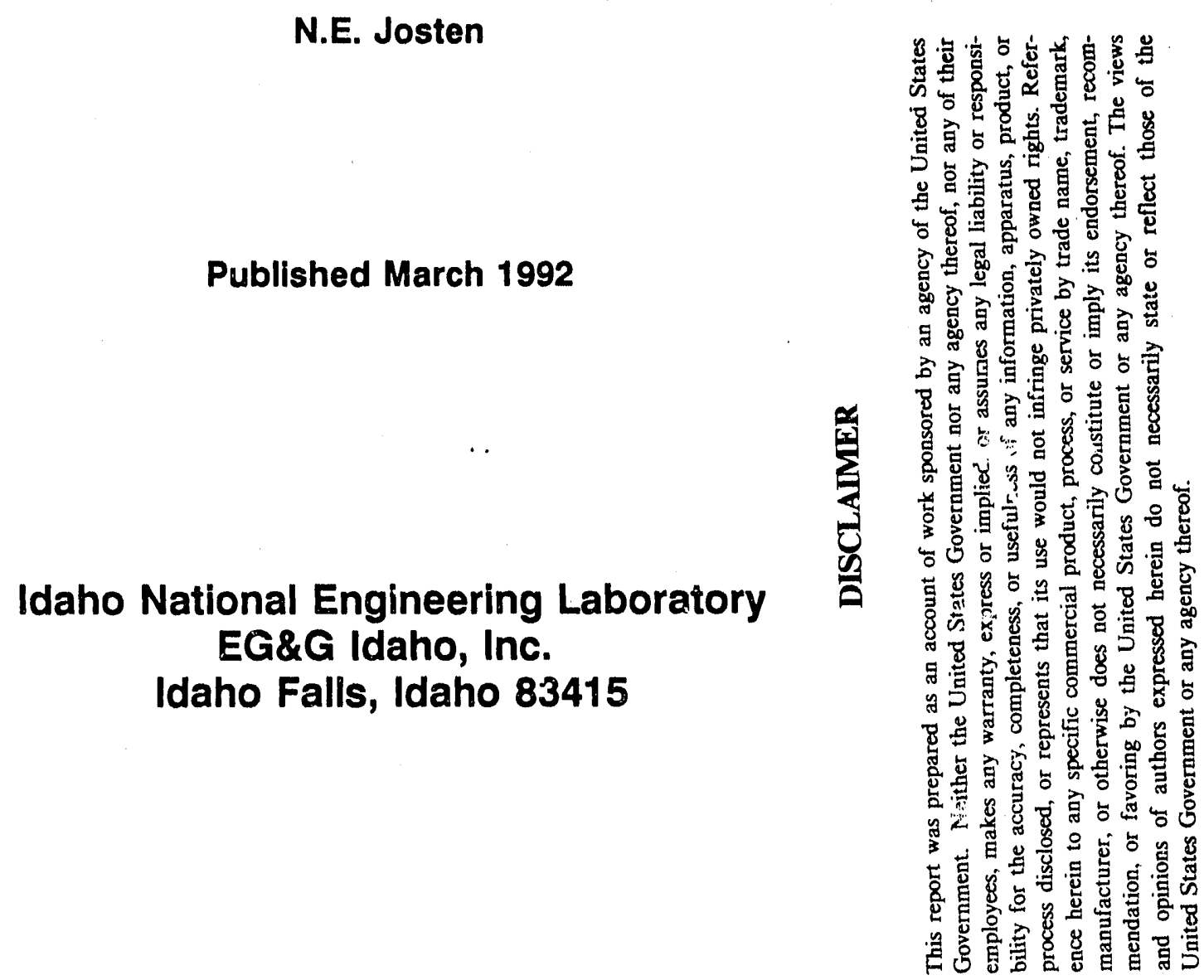
EVALUATION OF AIRBORNE THERMAL, MAGNETIC, AND ELECTROMAGNETIC CHARACTERIZATION TECHNOLOGIES

Prepared by:

Assholes \&. Gotten

Mlard,27,1992

N.E. Josten

Date

Approved by:

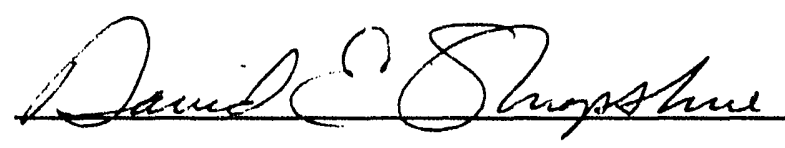

D.E. Shropshire
$3 / 27 / 92$

Date 


\section{ABSTRACT}

The Identification of Buried Structures (IBS) or Aerial Surveillance Project was initiated by the U.S. Department of Energy (DOE) Office of Technology Development to demonstrate airborne methods for locating and identifying buried waste and ordnance at the Idaho National Engineering Laboratory (INEL). Two technologies were demonstrated: (a) a thermal infrared imaging system built by Martin Marietta Missile Systems and (b) a magnetic and electromagnetic (EM) geophysical surveying system operated by EBASCO Environmental. The thermal system detects small differences in ground temperature caused by uneven heating and cooling of the ground by the sun. Waste materials on the ground can be detected when the temperature of the waste is different ihan the background ground temperature. The geophysical system uses conventional magnetic and EM sensors. These sensors detect disturbances caused by magnetic or conductive waste arú naturally occurring magnetic or conductive features of subsurface soils and rock. Both systems are deployed by helicopter.

Data were collected at four INEL sites. Tests at the Naval Ordnance Disposal Area (NODA) were made to evaluate capabilities for detecting ordnance on the ground surface. Tests at the Cold Simulated Waste Demonstration Pit were made to evaluate capabilities for detecting buried waste at a controlled site, where the location and depth of buried materials are known. Tests at the Subsurface Disposal Area and Stationary Low-Power Reactor-1 burial area were made to evaluate capabilities for characterizing hazardous waste at sites that are typical of DOE buried waste sites nationwide.

The Martin Marietta thermal system performed well for detecting ordnance and anomalous features of the ground surface but did not demonstrate any capabilities for detecting buried waste. At the NODA site, metallic objects as small as 6-in. long were detectable when located on or near the ground surface, and a possible chemical disposal area was identified. At the buried waste sites, a number of thermal anomalies were detected but were found to correspond with natural ground features such as vegetation, soil texture, and subtle topography. Overall, the thermal system demonstrated an impressive ability to rapidly survey large areas. Drawbacks included flight time restrictions imposed by nuances of the daily solar cycle and lack of a means to reference the thermal imagery to a ground coordinate system.

The EBASCO geophysical system easily detected the large buried waste sites, but data resolution was inadequate for detailed characterization of the waste or for detecting small isolated objects such as ordnance. Limited resolution resulted from poor spatial sampling, high elevation of sensors above ground, and inaccurate navigation. The geophysical system demonstrated an impressive ability to rapidly survey large areas. Although not fully demonstrated by the INEL survey, the airborne geophysical system may be ideally suited for reconnaissance site characterization where the objectives include investigating subsurface geology and hydrology. 


\section{SUMMARY}

The Identification of Buried Structures (IBS) or Aerial Surveillance Project was initiated in August 1991 by the U.S. Department of Energy (DOE) Office of Technology Development. The objective of the project was to demonstrate airborne methods for locating and identifying ordnance and buried waste at the Idaho National Engineering Laboratory (INEL). EG\&G Idaho, Inc., the prime DOE contractor at the INEL, was assigned to manage the IBS project. EG\&G Idaho submitted a request for proposal to solicit potential vendors who could provide technologies to meet the IBS project objectives. Two subcontracts were awarded: (a) Martin Marietta Missile Systems for a demonstration of their airborne thermal infrared imaging system and (b) EBASCO Environmental for a demonstration of their airborne magnetic and electromagnetic surveying system.

The technical approach to the IBS project was to evaluate the airborne systems based on their performance at three type areas. The first tests were performed at the Naval Ordnance Disposal Area (NODA), where metallic debris is scattered on the ground surface as the result of artillery tests and ordnance disposal operations. Tests were also conducted at the Cold Simulated Wasic Demonstration Pit where a variety of simulated waste materials are buried at known locations and depths. Finally, tests were conducted at the INEL Subsurface Disposal Area (SDA) and at the Stationary Low-Power Reactor-1 (SL-1) burial site. These two hazardous sites are typical of buried waste sites throughout the DOE complex.

The Martin Marietta thermal system tests were flown between October 15 and November 1, 1991. The EBASCO geophysical surveys were flown between October 21 and November 13, 1991. Data were compiled and evaluated, and draft final reports were delivered in January 1992. The two contractors presented their results in a meeting at INEL on February 21, 1992.

The Martin Marietta airborne system consists of a thermal infrared image recorder and a navigation system. An infrared camera is mounted on the underside of a helicopter where it continuously scans the ground surface during flight. The infrared camera detects small differences in the temperature of the ground surface caused by the effects of solar radiation on different ground materials. Data are recorded on a VHS video recorder. The navigation system locates the position of the helicopter, the flight elevation, and the camera view direction.

The Martin Marietta system proved to be a powerful tool for detecting and locating surface ordnance at the NODA site, even in the presence of substantial noise caused by sagebrush and rocks. Metallic objects as small as 6 in. produced clear thermal anomalies when observed during nighttime hours. During daytime hours, ...etallic objects could not be discerned from background clutter. In cases where clear ordnance anomalies were visible in the recorded imagery, Martin Marietta's image processor could be used to rapidly and automatically identify them. The capability for obtaining $100 \%$ ground coverage over large areas is an important attribute of the thermal system, with obvious advantages for ordnance detection operations. The main shortcoming of the ordnance detection 
system was the lack of means to reference the thermal imagery to a standard ground coordinate system. Without this capability, detected objects cannot be located for follow up work.

The thermal system also detected an anomaly believed to be associated with a chemical disposal area at NODA. The anomaly area was about $20 \times 30 \mathrm{ft}$ and was distinctly visible even during daylight hours. However, thermal imagery recorded at the SDA, SL-1, and the Cold Test Pit showed that features of the topography, vegetation, and ground texture can produce false anomalies that may have similar size, shape, and amplitude to the NODA chemical disposal anomaly. Because of this, thermal anomalies that are of potential importance for waste site characterization may be difficult to distinguish from naturally occurring features in some environments. Visual photography should be collected concurrently with the thermal data to help make anomaly distinctions.

Preliminary theoretical calculations made by EG\&G Idaho indicate that objects buried below 1 to $2 \mathrm{ft}$ will be undetectable by a thermal sytern because they will be beyond the penetration depth of solar radiation. Thes predictions differ substantially from those made by Martin Marietta and included in their final report. At the INEL, the thermal system exhibited no capabilities for detecting buried waste. Thermal anomalies detected at the SDA, SL-1, and the Cold Test Pit buried waste areas were all associated with ground surface features such as topography, vegetation, or soil texture. Due to the lack of promising results for detecting buried waste, no further field demonstrations are warranted. Future work should focus on establishing a sound theoretical basis for detection of buried waste.

The EBASCO airborne system consists of magnetic and electroniagnetic (EM) sensor arrays and a navigation system. The magnetic sensor array simultaneously measures magnetic total field and horizontal and vertical gradients of the total field. The magnetic sensors detect magnetic disturbances caused by ferrous metallic objects and iron bearing minerals in rocks. The EM sensor array measures induced EM responses at five separate frequencies corresponding with subsurface investigation depths throughout a range of approximately 50 to $400 \mathrm{ft}$. The EM sensors detect responses from conductive materials in the ground, which may include metallic objects and naturally occurring features of the subsurface geology. The navigation system locates the helicopter and records flight elevation.

The EBASCO system is well suited for reconnaissailce site characterization to locate large clandestine or abandoned waste burial areas. This capability was demonstrated by data collected at the SDA, SL-1, and the Cold Test Pit. The magnetic data showed clear anomalies associated with metallic waste at eacin of these sites, as well as background anomalies caused by magnetic minerals within the bedrock basalt. EM data collected at the Cold Test Pit also showed clear anomalies associated with the buried waste, but gave a lower resolution depiction of the distribution of buried materials than did the magnetic data. The magnetic and EM anomalies at the test sites were sufficiently strong to suggest that these sites would be easily detectable by a reconnaissance survey. 
The EBASCO airborne system is not suited for detecting small objects or for obtaining detailed characterization of known waste masses. The system does not have the resolution needed to make the fine distinctions that are required to identify small objects, locate pit boundaries, or map the distribution of materials within a waste pit. The limited resolution stems from three sources: poor spatial sampling, high sensor elevation, and inaccurate navigation. Problems in each of these areas can be corrected to some extent. However, due to the complexities involved with making measurements from a fast moving airborne platform, it is unlikely that the system's resolution can be increased to a level that approaches the resolution obtainable with ground systems.

The EBASCO system may also be applicable for characterizing regional geology and hydrology. Airborne geophysical surveys can contribute useful information to support groundwater studies, contaminant migration studies, or hazard assessment for a proposed reactor or waste repository construction site. The high data acquisition rates and ground coverage capabilities of the EBASCO airborne system are ideally suited for this purpose.

The thermal and geophysical data produced during the INEL demonstrations were adequate to establish the basic capabilities of the Martin Marietta and EBASCO technologies. These technologies will not be a miracle cure for waste site characterization. The technologies have very limited capabilities for meeting the most pressing DOE need - detailed characterization of known waste sites. However, there are several DOE characterization objectives that can be addressed. These applications were clearly demonstrated by the INEL test flights. 


\section{ACKNOWLEDGEMENTS}

Lyle Roybal, Bill Landman Jr., and Greg Miller of EG\&G Idaho, Inc. contributed valuable technical input, particularly to the discussion of thermal theory (Appendix A). Ed Van Eeckhout of Los Alamos National Laboratory and Larry Tinney, Lee Balick, and Kevin Forcade of EG\&G Energy Measurements Remote Sensing Laboratory made technical reviews of this document, which provided a wider scope and strengthened the conclusions. 


\section{CONTENTS}

ABSTRACT $\ldots \ldots \ldots \ldots \ldots \ldots \ldots \ldots \ldots \ldots \ldots \ldots \ldots \ldots \ldots \ldots \ldots \ldots \ldots \ldots \ldots \ldots \ldots \ldots \ldots$

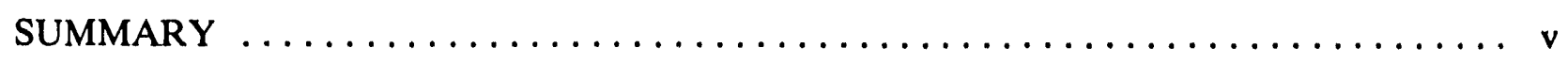

ACKNOWLEDGEMENTS $\ldots \ldots \ldots \ldots \ldots \ldots \ldots \ldots \ldots \ldots \ldots \ldots \ldots \ldots \ldots$ viii

ACRONYMS $\ldots \ldots \ldots \ldots \ldots \ldots \ldots \ldots \ldots \ldots \ldots \ldots \ldots \ldots \ldots \ldots \ldots \ldots \ldots \ldots \ldots \ldots$

1. INTRODUCTION $\ldots \ldots \ldots \ldots \ldots \ldots \ldots \ldots \ldots \ldots \ldots \ldots \ldots \ldots \ldots \ldots$

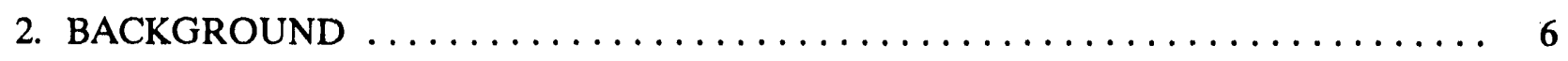

3. SITE DESCRIPTIONS $\ldots \ldots \ldots \ldots \ldots \ldots \ldots \ldots \ldots \ldots \ldots \ldots \ldots \ldots \ldots$

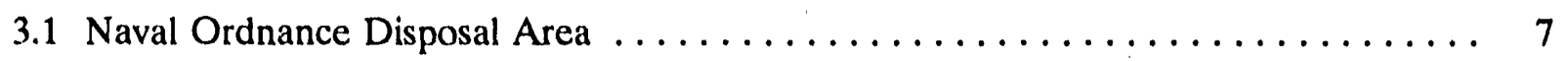

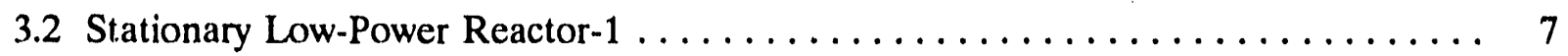

3.3 Subsurface Disposal Area $\ldots \ldots \ldots \ldots \ldots \ldots \ldots \ldots \ldots \ldots \ldots \ldots \ldots$

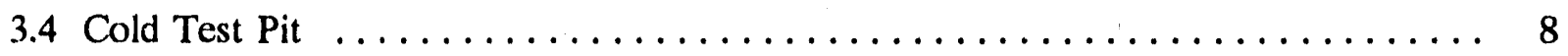

4. MARTIN MARIETTA INFRARED IMAGING SYSTEM $\ldots \ldots \ldots \ldots \ldots \ldots \ldots \ldots$

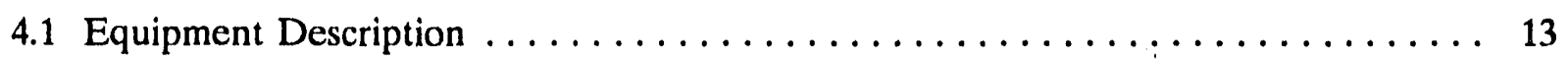

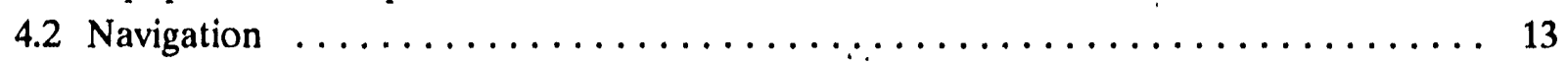

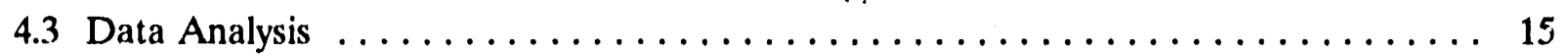

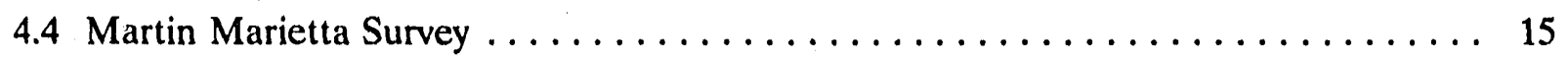

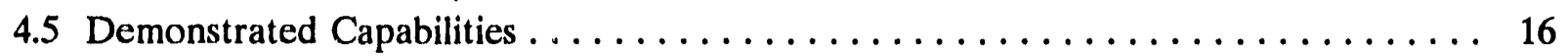

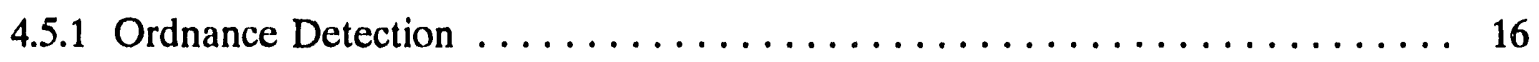

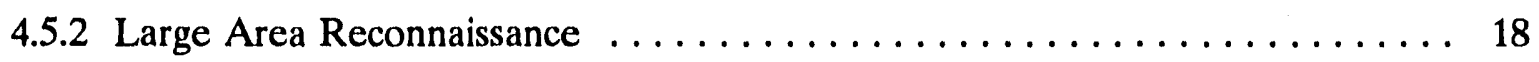

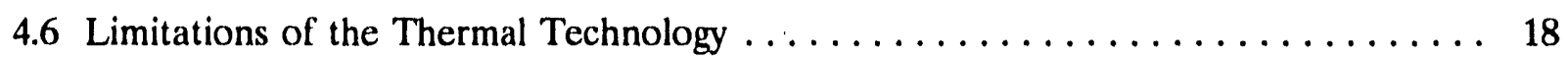

4.6.1 Surface Object (Ordnance) Detection $\ldots \ldots \ldots \ldots \ldots \ldots \ldots \ldots \ldots$

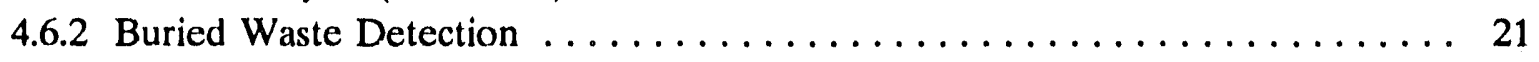

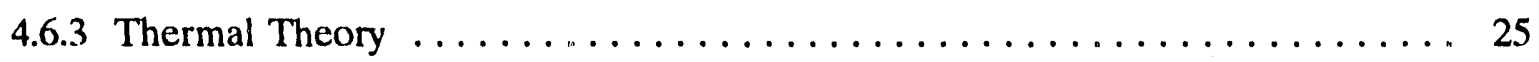

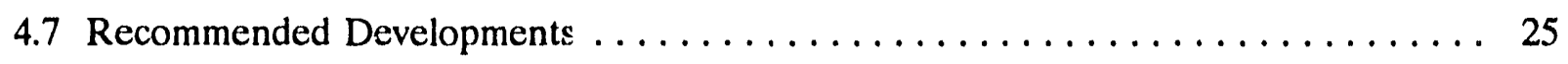




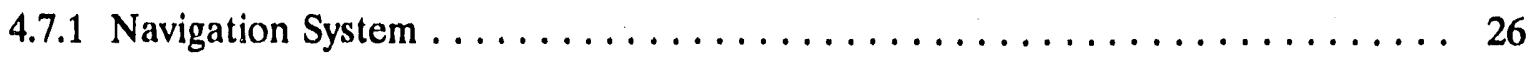

4.7..2 Visible Spectrum Recorder .......................... 26

4.7.3 Theoretical Basis for Buried Waste Applications ................ 26

5. EBASCO MAGNETIC AND ELECTROMAGNETIC SURVEY SYSTEM $\ldots \ldots \ldots 28$

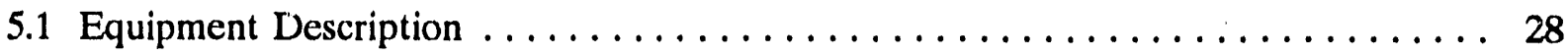

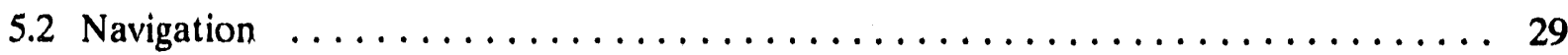

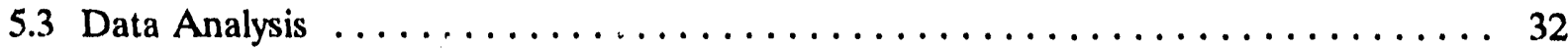

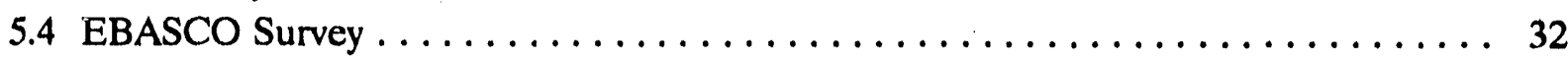

5.5 Demonstrated Capabilities .............................. 33

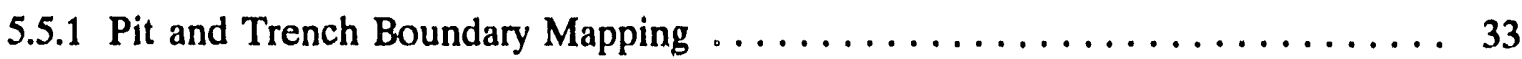

5.5.2 Large Area Reconnaissance $\ldots \ldots \ldots \ldots \ldots \ldots \ldots \ldots \ldots \ldots \ldots . \ldots . \ldots . \ldots 33$

5.6 Limitations of Airborne Geophysical Technology $\ldots \ldots \ldots \ldots \ldots \ldots \ldots \ldots . \ldots 36$

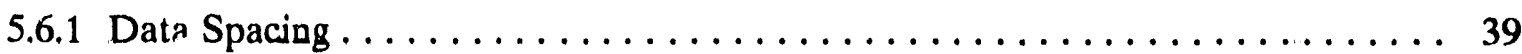

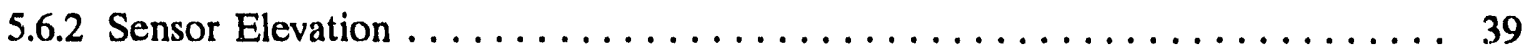

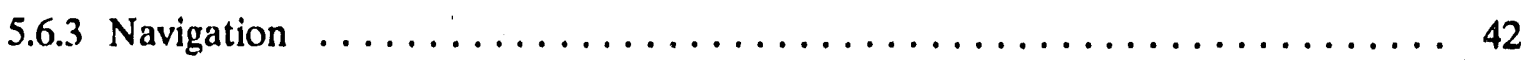

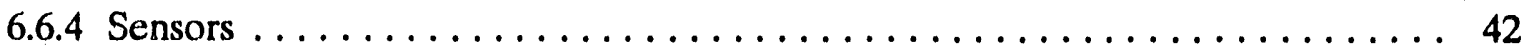

5.7 Recommended Developments $\ldots \ldots \ldots \ldots \ldots \ldots \ldots \ldots \ldots \ldots \ldots \ldots \ldots .42$

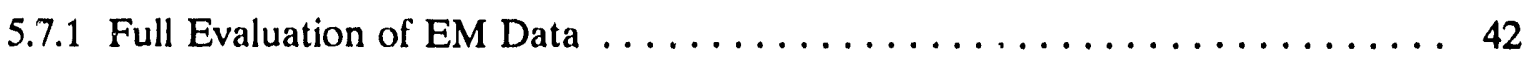

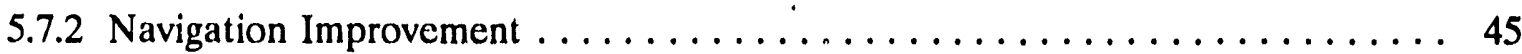

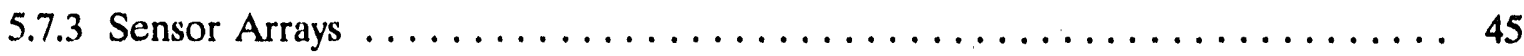

5.7.4 Regional Geologic/Hydrologic Characterization $\ldots \ldots \ldots \ldots \ldots \ldots \ldots \ldots 45$

6. ADVANTAGES OF SYSTEM INTEGRATION $\ldots \ldots \ldots \ldots \ldots \ldots \ldots \ldots \ldots \ldots$

7. DEPARTMENT OF ENERGY APPLICATIONS $\ldots \ldots \ldots \ldots \ldots \ldots \ldots \ldots \ldots$

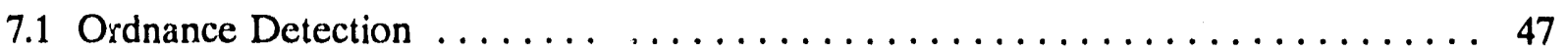

7.2 Reconnaissance Searches for Unknown Waste Sites $\ldots \ldots \ldots \ldots \ldots \ldots \ldots . \ldots 4$

$7.3 \mathrm{Geologic/Hydrologic}$ Characterization $\ldots \ldots \ldots \ldots \ldots \ldots \ldots \ldots \ldots \ldots, 48$

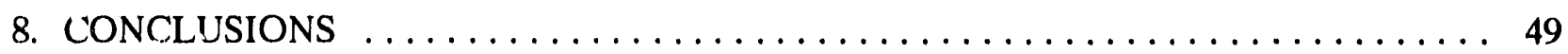

8.1 Martin Marietta Thermal System $\ldots \ldots \ldots \ldots \ldots \ldots \ldots \ldots \ldots \ldots \ldots \ldots . \ldots 49$

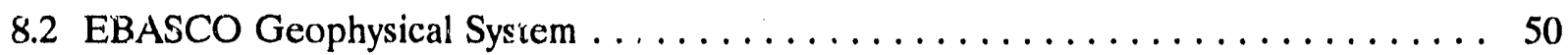




\section{FIGURES}

1. Photograph of the Martin Marietta thermal imaging system used for the INEL

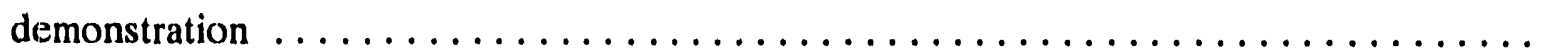

2. Photograph of the EBASCO airborne geophysical system used for the INEL demonstration

3. Map showing the INEL boundary, location of selected facilities, roads, and local geographic features

4. Plan map of the INEL RWMC showing the location of the SDA $\ldots \ldots \ldots \ldots$

5. Plan map showing layout of the Cold Test Pit $\ldots \ldots \ldots \ldots \ldots \ldots \ldots \ldots \ldots$

6. Schematic drawing of the Martin Marietta thermal imaging unit $\ldots \ldots \ldots \ldots \ldots$

7. Thermal image from NODA area showing several objects scattered on the ground surface

8. Oblique (a) and overhead (b) image of a thermal anomaly at the NODA site .

9. Thermal images of NODA site illustrating the influence of time of day on the clarity of thermal anomalies

10. Thermal image (a) and visual spectrum image (b) of a portion of Pit 9 at the SDA (see Figure 4 for location)

11. Thermal image (a) and visual spectrum image (b) of the SL-1 burial area showing clear anomalies (shown by arrows) associated with two waste disposal trenches

12. Thermal image (a) and visual spectrum image (b) of Cold Test Pit $\ldots \ldots \ldots \ldots \ldots$

13. Schematic illustration showing subsurface zones categorized according to the dominant thermal influence 
14. Schematic drawing and description of the EBASCO magnetic sensor array used for the INEL survey

15. Schematic drawing and description of the EBASCO electromagnetic sensor array used for the INEL survey

16. EBASCO vertical gradient magnetic data over a portion of the SDA showing linear anomaly trends associated with waste burial trenches

17. EBASCO horizontal gradient magnetic data over the NODA site impact area $\ldots \ldots \ldots 35$

18. EBASCO vertical gradient magnetic data (a) and electromagnetic data (b) over the Cold Test

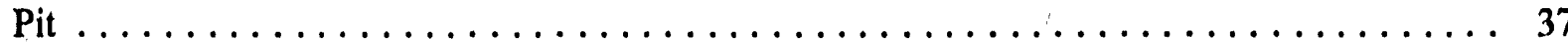

19. Comparison of vertical gradient magnetic data collected by the EBASCO airborne system (a) and by conventional ground-based surveying $(b)$ at the Cold Test Pit $\ldots \ldots \ldots \ldots \ldots$

20. Comparison of data point density for conventional ground survey (a) and EBASCO airborne

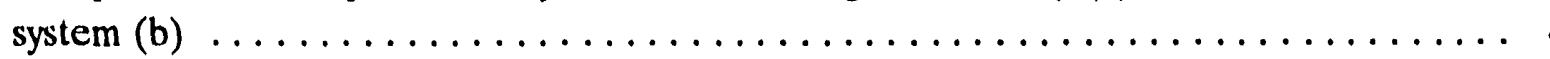

21. Magnetic model depicting the effects of sensor elevation for shallowly buried objects . . . 41

22. Vertical gradient profiles from EBASCO's survey of the SDA showing systematic offset of anomaly peaks

23. Thirty-three $\mathrm{kHz}$ EM quadrature profiles from the Cold Test Pit showing systematic offset of anomaly peaks

\section{TABLES}

1. Description of zones in simulated waste pit 


\section{ACRONYMS}

$\begin{array}{ll}\text { ARA-II } & \text { Auxillary Reactor Area-II } \\ \text { BWID } & \text { Buried waste integrated demonstration } \\ \text { EM } & \text { electromagnetic } \\ \text { IBS } & \text { Identification of buried structures } \\ \text { DOE-HQ } & \text { U.S. Department of Energy-Headquarters } \\ \text { DOE-ID } & \text { U.S. Department of Energy-Idaho } \\ \text { GPS } & \text { Global Positioning System } \\ \text { INEL } & \text { Idaho National Engineering Laboratory } \\ \text { NODA } & \text { Navai Ordnance Disposal Area } \\ \text { RWMC } & \text { Radioactive Waste Management Complex } \\ \text { SDA } & \text { Subsurface Disposal Area } \\ \text { SL-1 } & \text { Stationary Low-Power Reactor-1 }\end{array}$




\section{EVALUATION OF AIRBORNE THERMAL, MAGNETIC, AND ELECTROMAGNETIC CHARACTERIZATION TECHNOLOGIES}

\section{INTRODUCTION}

The Identification of Buried Structures (IBS) or Aerial Surveillance Project was initiated in August 1991 by the U.S. Department of Energy (DOE) Office of Technology Development through their Idaho Field Office (DOE-ID). EG\&G Idaho, Inc., the prime DOE contractor at the Idaho National Engineering Laboratory (INEL), was assigned to manage the IBS Project. The objective of the project was to demonstrate airborne methods for locating and identifying ordnance and buried waste at the INEL.

The IBS Project was placed under the direction of the Buried Waste Integrated Demonstration (BWID) Program. INEL is the lead laboratory for the BWID Program. A Request for Proposal was sut,mitted to solicit potential vendors who could provide technologies to meet the IBS Project objectives. Two helicopter-mounted systems were selected for further evaluation. Subcontracts were awarded to Martin Marietta Missile Systems of Orlando, Florida, and to EBASCO Environmental Services, Inc. of Idaho Falls, Idaho.

The Martin Marietta system is a thermal imaging technoiogy that uses a nonproprietary infrared camera adapted for airborne deployment (see Figure 1). The thermal imaging technology was developed to detect land mines and has been used successfully for this purpose. The EBASCO system is a standard magnetic field and induced electromagnetic field sensing technology, also adapted for airborne deployment (see Figure 2). The system is traditionally used for mineral exploration but was adapted for the special purposes of the IBS Project. A similar system had been previously used at the Rocky Mountain Arsenal in Colorado to locate the boundaries of spent ordnance burial trenches.

The technical approach to the IBS Project was to evaluate the airborne systems based on their performance at three type areas. The sites were chosen to provide a range of target detection problems. The first tests were performed at the Naval Ordnance Disposal Area (NODA), which is known to contain scattered ordnance. This site tested capabilities for locating and identifying small metallic objects at shallow depths. Tests were also conducted at the Cold Simulated Waste Demonstration Pit located near the Radioactive Waste Management Complex (RWMC). The Cold Test Pit contains simulated waste materials and is designed to represent conditions at the RWMC. The locations and depths of items buried in the pit are known. The Cold Test Pit surveys demon- 


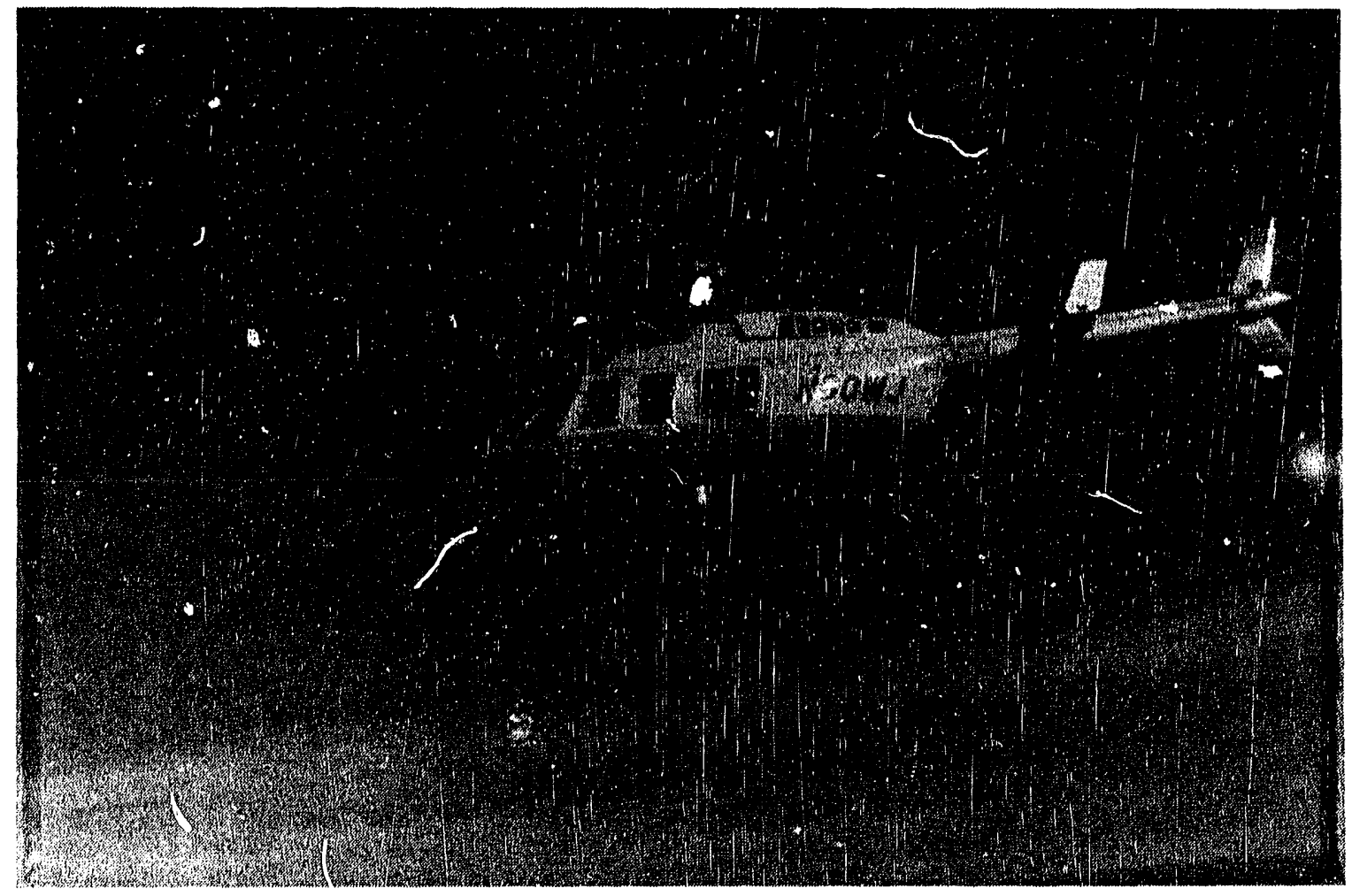

Figure 1. Photograph of the Martin Marietta thermal imaging system used for the INEL demonstration. The infrared camera is mounted on the underside of the helicopter in the ball-shaped housing. 


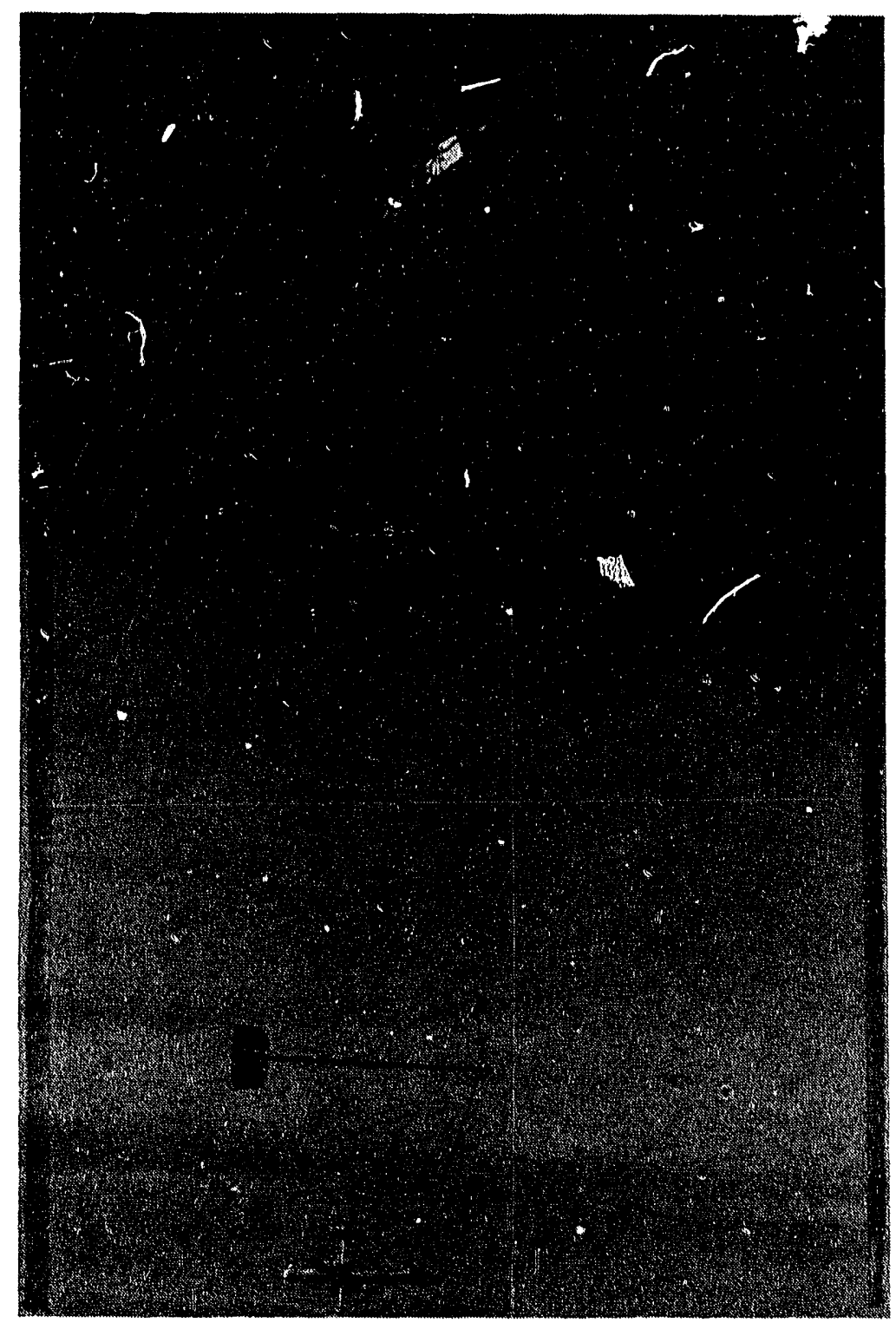

Figure 2. Photograph of the EBASCO airborne geophysical system used for the INEL demonstration. The magnetic sensors (shown here) are mounted on stabilized housing and suspended from a tow cable 100-ft below the helicopter. The electromagnetic sensors are mounted on a different housing and flown separately. 
strated capabilities for detecting buried waste in s nonhazardous, well documented environment. Finally, two hazardous waste sites were surveyed to demonstrate capabilities for characterizing buried waste in settings that are typical of buried waste sites throughout the DOE complex. These tests were performed at the RWMC Subsurface Disposal Area (SDA) and at the Stationary Low-Power Reactor-1 (SL-1) burial area located near the Auxiliary Reactor Area-II. The locations of these areas within the INEL are shown in Figure 3.

The Martin Marietta test fights began on October 15, 1991, and were completed on November 1, 1991. The EBASCO test fights began on October 21, 1991, and were completed on November 13, 1991. Data were compiled and analyzed, and draft reports were delivered to EG\&G Idaho, Inc. and DOE Headquarters (DOE-HQ) on January 13, 1992. A review was held at INEL on February 21, 1992, during which both contractors presented their final results to attendees from DOE-HQ, DOE-ID, EG\&G Idaho, and several national laboratories.

This report summarizes the results from the Martin Marietta and EBASCO demonstrations. The report does not furnish exhaustive data analysis of the test sites. Instead, the evaluation focuses on the capabilities and limitations of these technologies for meeting DOE waste characterization objectives. In most cases, exanuples from the INEL data sets are used to illustrate these capabilities and limitations. To the exten: that the chosen test sites are typical of DOE sites nationwide, the INEL demonstrations constitute a relevant test of these technologies. This evaluation will hopefully promote equally relevant future development and usage of these technologies. 


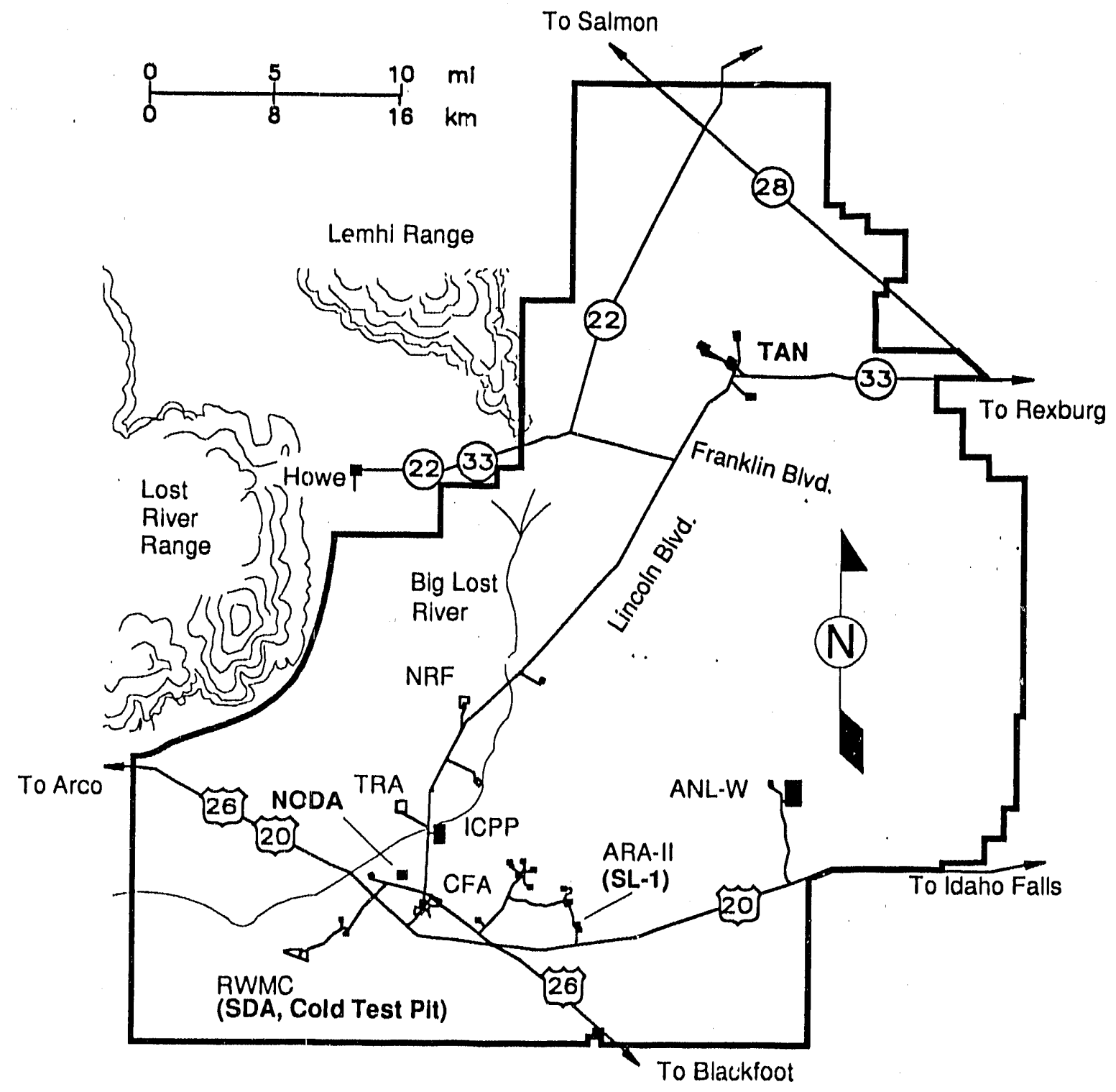

Figure 3. Map showing the INEL boundary, location of selected facilities, roads, and local geographic features. The airborne survey sites are in the southern portion of the INEL and highlighted by bold lettering. 


\section{BACKGROUND}

Waste storage at the RWMC began $i$, the 1940s and continues today. Pits and trenches within the SDA of the RWMC contain an estimated 2 million $\mathrm{ft}^{3}$ of contaminated buried waste intermixed with 6 million $\mathrm{ft}^{3}$ of fill dirt. At the SDA, wash was buried in cardboard boxes, steel drums, and plywood crates depending on the nature of the waste and the dispssal practices of the time. Original records of what was buried and where it was buried are often inaccurate and are too general to be useful for retrieval and remediation purposes. Site characterization activities are undertaken to supply the information on extent and nature of waste that is needed to support planning for retrieval and remediation.

During the 1940 s and 1950 s, military tests and ordnance disposal operations left spent and live ordnance scattered throughout areas of the INEL. Because of the ordnance hazard, ground-based ordnance searches precede all new construction at the INEL. This procedure is not satisfactory because ground-based searches are tedious, and search crews may inadvertently detonate ordnance.

These INEL sites typify some of the more common site chararterization issues that DOE faces in the effort to remediate DOE facilities nationwide. Substantial money and effort have been invested in technologies to perform this characterization. The airborne demonstrations discussed in this report are being evaluated for this purpose, 


\section{SITE DESCRIPTIONS}

The INEL sites that were surveyed during the demonstrations by Martin Marietta and EBASCO are described briefly in the following sections. The descriptions give information regarding the types of materials that are present at each site and the methods by which they were deposited. A brief statement is also made regarding the kej waste characterization objectives for each site.

\subsection{Naval Ordnance Disposal Area}

The NODA is located on approximately 50 acres of land in the southern part of the INEL (see Figure 3). NODA was used for open pit burning of explosive ordnance and reactive chemicals. Prior to its use as a disposal facility, NODA was part of a naval gunnery range and received shells from assorted large caliber cannons. As a result of these activities, the NODA site is littered with explosive debris including shell fragments, unexploded shells, and possibly live ordnance. The site may also contain areas of chemically contaminated soils. The NODA site is somewhat unique in that the waste materials of interest uccur mostly at the ground surface.

The first characterization objective for NODA is to locate live ordnance so that the site can be cleared for safe access. A secondary objective is to locate and identify contaminated soils.

\subsection{Stationary Low-Power Reactor-1}

The SL-1 burial area is located approximately $1600 \mathrm{ft}$ northeast of the ARA-II (see Figure 3). ARA-II is the site of a 1961 reactor accident, and the SL-1 burial area contains waste materials generated by cleanup operations following the accident. The burial area consists of three side-by-side trenches, approximately $10-\mathrm{ft}$ deep. The damaged reactor was disassembled, and the materials were either randomly dumped into the trenches by trucks or were dropped by cranes. The trenches were then backfilled with several feet of clean soil.

Future characterization efforts at the SL-1 burial area will focus on locating key materials within the waste mass (such as components of the reactor core) and on the spread of radioactive contamination into the surrounding soils. These are difficult remote sensing problems, but are quite typical for DOE waste sites. The location, size, shape, and general content of the trenches are already known from historical records. 


\subsection{Subsurface Disposal Area}

The SDA is a 96 acre section of the INEL RWMC (see Figures 3 and 4). Numeruus pits and trenches are laid out side-by-side over the area. The size and depth of the pits vary widely. In general, depth to the top of the waste varies between 3 and $10 \mathrm{ft}$ (Yokuda, 1991). Depth to bedrock varies between 10 to $30 \mathrm{ft}$ (Anderson and Lewis, 1989). Virtually any imaginable waste produced by nuclear facilities is buried at the SDA.

Historical records of burial operations at the SDA are often incomplete or incorrect, and in many cases, the records are inadequate for planning remedial activities. Site characterization is being actively pursued to fill this gap. The SDA characterization objective is to compile as much information as possible on the nature, quantity, and location of waste materials.

\subsection{Cold Test Pit}

The Cold Test Pit is a nonhazardous, simulated waste burial pit located adjacent to the RWMC (see Figure 4). The pit was constructed in 1989 to serve as a field laboratory for testing characterization and remediation technologies. For this reason, the Cold Test Pit was designed to simulate conditions at the SDA. The pit is about $50-\mathrm{ft}$ wide $\times 150-\mathrm{ft}$ long and has five zones laid out as shown in Figure 5. Each zone contains a simulated waste mass that represents a set of conditions found at the SDA (see Table 1). The waste masses include many different types of materials and containers, both metallic and nonmetallic. Burial depths and spacing between objects and groups of objects is variable, but is well documented in the construction records (Loomis, 1989).

The Cold Test Pit is an ideal proving ground for characterization technologies because it provides a straightforward means to judge both sensitivity (i.e., what types of materials will a system detect?) and resolution (i.e., how clearly does the system distinguish the detected materials from its neighbors?). 


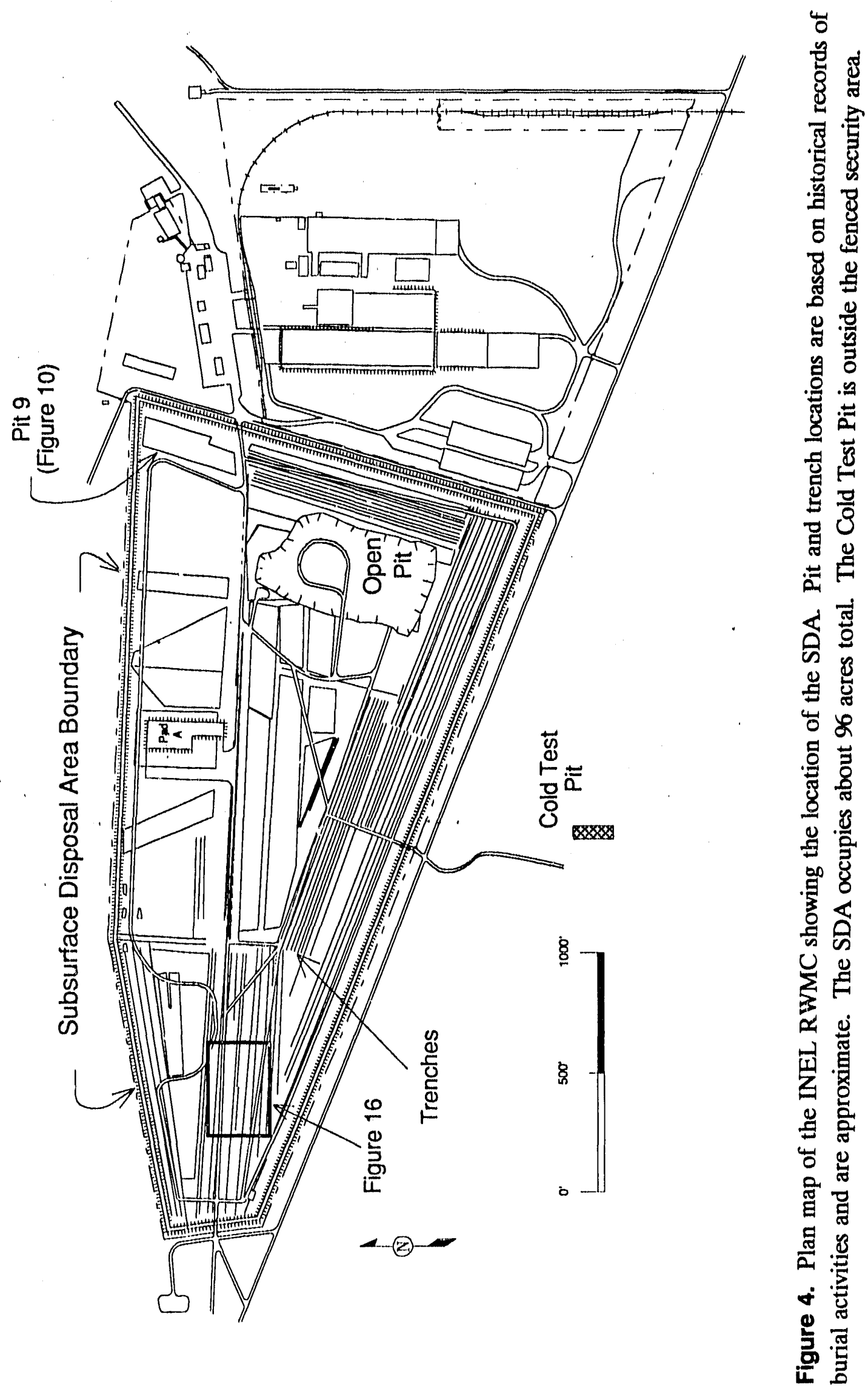




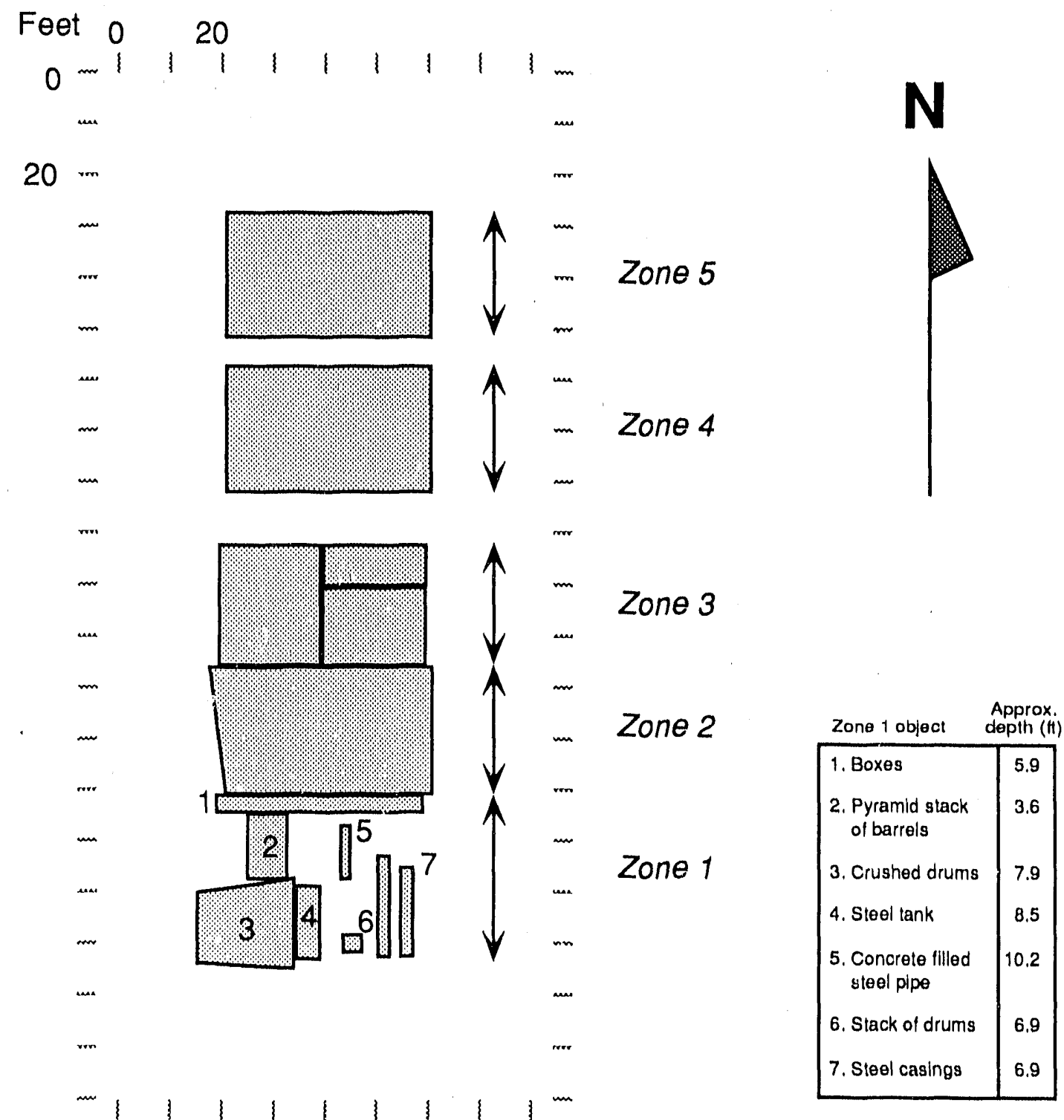

Figure 5. Plan map showing layout of the Cold Test Pit. The Cold Test Pit contains a variety of simulated waste including barrels, crates, scrap metal, and boxes of rags buried at depths ranging from 3 to $10 \mathrm{ft}$. Individual objects in Zone 1 are listed in the table (inset). A description of materials buried in other zones is given in Table 1 . The Cold Test Pit was constructed to simulate the conditions at the SDA. The pit size is about $50 \times 150 \mathrm{ft}$. 
Table 1. Description of zones in simulated waste pit.

Zone $\quad$ Description

1. Large Objects

2. Stacked Boxes

3. Stacked Drums

4. Random Dump Drums and Boxes

5. Random Dump Drums
Contains pipes, drums, tanks, concrete vaults, and plywood boxes filled with primarily wood, paper, plastic, and metal. The locaiion of each object is known.

$4 \times 4 \times 8 \mathrm{ft}$ cardboard boxes filled with metal debris, large metal objects, concrete, and asphalt. Upper boxes contain primarily metal.

Stacked drums containing sludge, paper, wood, metal, concrete, and glass. Most drums are cardboard with the remaining being steel.

Randomly distributed cardboard drums, steel drums, and cardhoard boxes. Containers are concrete and glass.

Randomly distributed cardboard and steel drums containing sludge, paper, wood, metal, concrete, and glass. 


\section{MARTIN MARIETTA INFRARED IMAGING SYSTEM}

The Martin Marietta infrared imaging system detects thermal anomalies on the earth's surface by means of an infrared camera that is scanned across the ground. The system's utility for waste characterization depends on two factors: (a) the extent to which buried (or surface) waste creates temperature anomalies on the ground surface, and (b) the ability of the infrared camera to detect these anomalies, which may be quite subtle and/or small and to distinguish them from anomalies caused by nonwaste materials.

The waste types that are of interest in site characterization do not generate heat. They do, however, have widely varying capacities for conducting and retaining heat. Under the influence of an external heat source, such as the sun, buried waste materials on the ground surface will heat up and cool down at different rates than the surrounding soils creating a cyclical temperature contrast between the two media. Solar induced temperature differentials permit waste objects on the ground surface to be detected directly by infrared photography during certain times of the day. Buried waste may still be detectable, although not directly, if (a) the waste is within the soil zone that is influenced by solar radiation or is subject to heating by some other heat source, and (b) any resulting subsurface temperature anomaly is conducted back to the ground surface where it can be detected.

Solar induced thermal anomalies have been routinely observed for objects that are on the ground surface or shallowly buried (less than $1 \mathrm{ft}$ ). The anomalies in this case are distinct but can be small. High resolution cameras are required to detect the anomalies. Thermal anomalies have not been demonstrated for more deeply buried waste. Preliminary theoretical calculations made by Martin Marietta suggest that temperature anomalies from 2 to $14^{\circ} \mathrm{C}$ can occur at the ground surface immediately above large objects buried down to $6 \mathrm{ft}$ (Martin Marietta, 1991). Calculations performed by EG\&G Idaho predict that waste buried below $1 \mathrm{ft}$ would produce anomalies smaller than $0.1^{\circ} \mathrm{C}$, which is the detection limit for the Martin Marietta system (Miller, 1991). The EG\&G Idaho calculations are based on a more rigorous thermal model and are presented, along with a discussion, in Appendix $\mathrm{A}$ of this report. The discrepancy between the Martin Marietta and EG\&G Idaho calculations underscores a clear need for a firm theoretical framework for evaluating thermal characterization of buried waste. At present, there is little basis for interpreting the thermal data collected by Martin Marietta at the INEL buried waste sites. 


\subsection{Equipment Description}

The Martin Marietta imaging system consists of an Inframetrics Model IRTV-445G high resolution thermal detector mounted on the underside of a Bell Long Ranger helicopter (see Figure 6). The infrared detector has a spectral range of 8 to 12 micrometers. The field of view is $21 \times 28$ degrees under normal magnification. The unit also operates in a $4 x$ magnification mode with a 5.25 $x 7$ degree field of view. The sensor platform is gimballed to counter the effects of aircraft roll, pitch, and yaw enabling the camera to scan a continuous path along the ground beneath the helicopter. Images from the camera are displayed in real-time on a video monitor and are recorded on a super VHS video recorder. Azimuth, elevation, field of view, time and date are continuously determined and are recorded with the video data.

\subsection{Navigation}

Helicopter navigation was accomplished by several methods. Loran-C, a government maintained long-range electronic positioning system, was used to navigate the helicopter to the site of interest. Once on site, the helicopter was navigated by either of two methods depending on the nature of the mission. For detailed mapping of small surface ordnance at the NODA site, the helicopter was flown at an elevation of $200-\mathrm{ft}$ above ground level. At this elevation the sensor footprint is quite narrow. To maintain complete ground coverage, personnel were stationed on the ground (with flashlights during night work). This gave the pilot a visual aid to help position the helicopter along closely spaced flight lines. For mapping of buried waste sites, the helicopter was flown at elevations from 400 to 1000 - $\mathrm{ft}$ above ground level. At this elevation, the sensor footprint is considerably larger and it was possible to navigate using the thermal images themselves to monitor ground coverage. In addition to electronic positioning and visual navigation, a Global Positioning System (GPS) was operated during the test flights. GPS was found to be unreliable due to inadequate satellite coverage.

Apart from its function to position the helicopter, the navigation system is also relied on to reference the recorded thermal images to a ground coordinate system. For a single recorded inage, ground coordinates can be theoretically computed based on the instantaneous aircraft position, altitude, sensor view angle, and sensor magnification. In practice, this approach did not work well because the navigation data were not sufficiently accurate. In the end, ground positions were estimated by identifying cultural features on the thermal images (e.g., roads or fences) and referencing these to topographic or site engineering maps. 


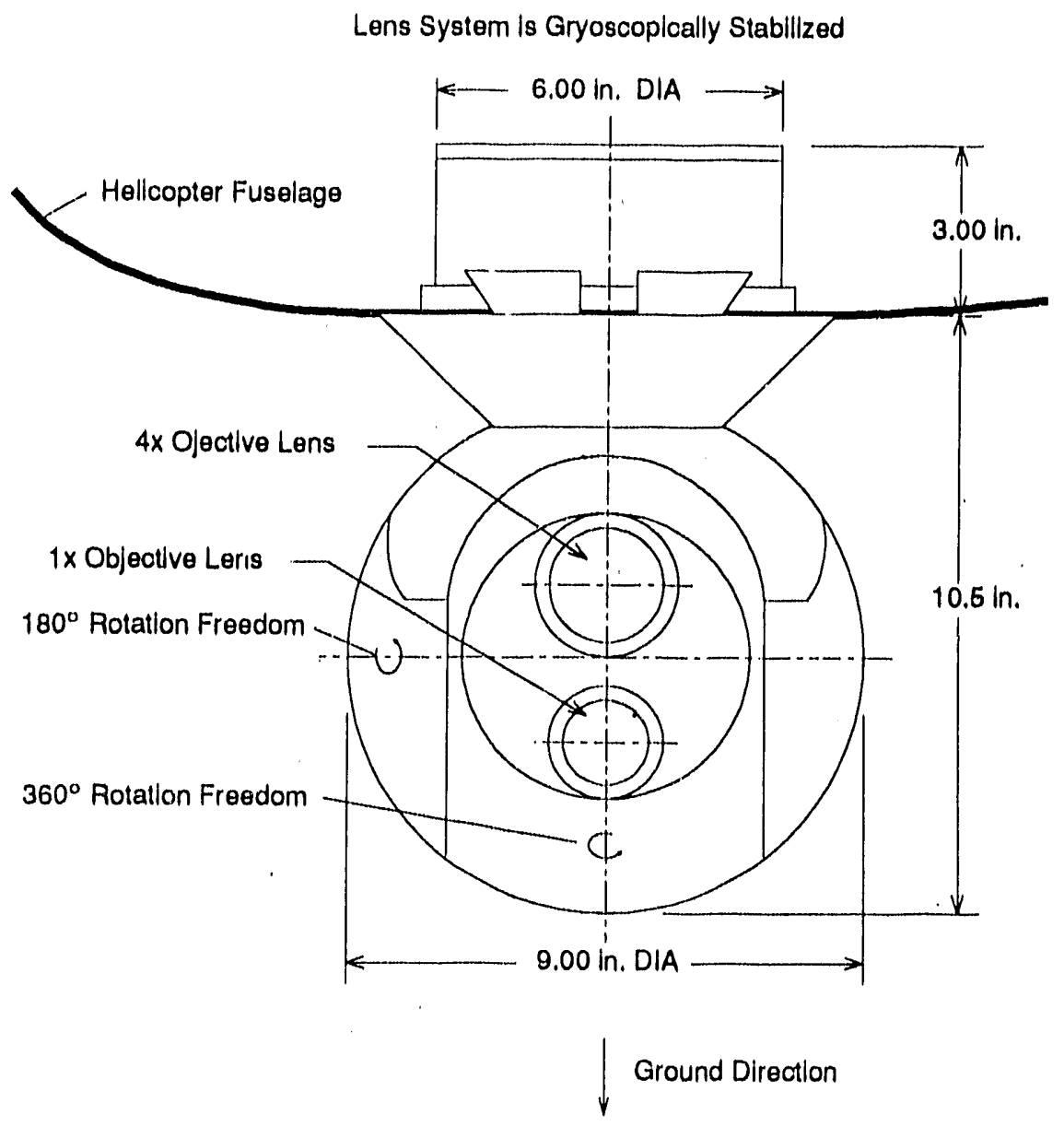

Figure 6. Schematic drawing of the Martin Marietta thermal imaging unit. The unit is mounted on the underside of the helicopter and collects infrared images of the ground during flight. Ground coverage depends on the lens magnification and flight elevation. For the INEL survey, the camera footprint varied between about $48 \times 36 \mathrm{ft}$ for low-level high magnification flights, to about $1200 \times 900$ $\mathrm{ft}$ for high-level wide angle flights. The image resolution is better for smaller view fields. 


\subsection{Data Analysis}

In post-processing, the analog video data are digitized frame by frame to produce a 400 by 425 element digital image. Each element is assigned a gray scale value dependent on the average gray value in the corresponding area of the analog image. The gray values depict relative ground temperatures. The unenhanced data are then examined to determine if additional processing is required. A wide variety of spatial filters are available for enhancing the images. These filters are effective in cases where signal and noise are distinguishable on the hasis of spatial wavelength. The images can also be converted to binary images using a gray scale threshold operation. This procedure is effective for isolating object outlines in cases where the signal of interest stands well above (or below) the background.

Martin Marietta also uses a proprietary image processing technology that can perform automatic interpretation of the digital imagery in real time. This processing was not performed during the actual flights but was tested during post-processing. The system scans each digital image and identifies thermal features that conform to specified search criteria. Search criteria may include size, shape, and/or thermal amplitude (gray scale value). Automated image processing is effective in cases where targets of interest are distinguishable from noise on the basis of these parameters. When effective, Martin Marietta's image processing technology interprets images with remarkable speed and consistency.

\subsection{Martin Marietta Survey}

Martin Marietta conducted thermal surveys of the four INEL sites during the period from October 15 to November 1, 1991. Fourteen separate missions were flown including many repeat surveys of the same area at different times of the day. Flight elevation and sensor magnification were varied to suit the objectives for each site. The NODA site was flown at lower elevations in order to resolve detailed thermal signatures from ordnance. The Cold Test Pit, SDA, and SL-1 were flown at higher elevations. The Martin Marietta helicopter was not permitted to fly within $1000 \mathrm{ft}$ of the open pit at the SDA (see Figure 4). Because of this restriction, only oblique images could be collected for Pit 9 of the SDA. 


\subsection{Demonstrated Capabilities}

\subsubsection{Ordnance Detection}

The Martin Marietta thermal imaging system proved to be extremely effective for detecting ordnance at the NODA site. The system also demonstrated some potential as a reconnaissance tool by detecting and locating a large thermal anomaly at a sus ected chemical disposal site inside the fenced perimeter of NODA.

Figure 7 is an example image from the NODA site that shows clear anomalies indicating ordnance scattered on the ground surface. This image was taken at about 9:00 p.m., and the ordnance appear as black (hot) anomalies against a cool background. The observed temperature differential is a direct consequence of the contrast in heat capacity and thermal conductivity between the metal shell cases, which tend to retain heat for some time, and the soils and vegetation, which absorb and dissipate heat rapidly. By late evening hours, the soil and vegetation have cooled while the ordnance continues to radiate heat. The image in Figure 7 is completely unenhanced and demonstrates the resolution that is achievable. The indicated objects range from 6 in. to several feet in length.

Martin Marietta tested their image processor on portions of the NODA data and found it to be quite successful for rapidly identifying ordnance such as those shown in Figure 7. This result may be attributed to the high amplitude of the ordnance anomalies, which allows them to be easily distinguished from background clutter. Anomaly amplitude was, in fact, the sole criteria used by the image processor to identify ordnance. Thermal images collected during non optimum times of day proved more difficult to evaluate with the image processor. In these images, the ordnance could not be distinguished from sagebrush and rocks on the basis of anomaly amplitude alone. Results were not improved by using more restrictive search criteria that classified anomalies according to size and shape as well as amplitude. This is not surprising since sagebrush and rocks may have sizes and shapes that are quite similar to ordnance, particularly when viewed from $200 \mathrm{ft}$ overhead. In cases where valid criteria exist for distinguishing anomalies of interest from those that are not, image processing will be valuable for analyzing the massive data sets generated by thermal surveys. In many cases, particularly for buried waste, there may be no such criteria, and the data will require more careful interpretation. 


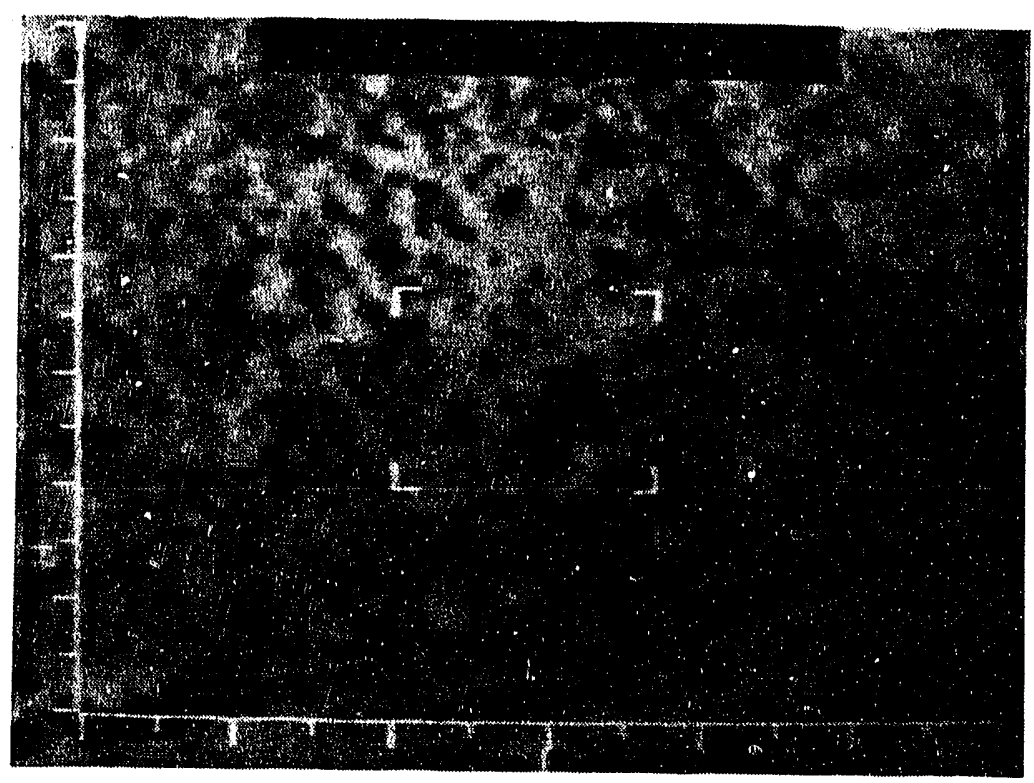

NODA - 9 October 1991 - 9:00 p.m.

Figure 7. Thermal image from NODA area showing several objects scattered on the ground surface. The objects appear as dark (hot) anomalies against a light (cold) background. This image was taken under optimal conditions and required no image enhancement. The thermal imaging system consistently detected objects as small as 6 in. in length if they were at or very near the ground surface. Note that the metallic objects are easily distinguished from background clutter caused by sagebrush and rocks. 
The most distinguishing feature of the thermal imaging technology is its ability to rapidly interrogate large ground areas. Because a wide swath is mapped by each pass of the aircraft, complete ground coverage can usually be obtained. In searching for ordnance, this is a major advantage over remote sensing systems that make discrete point measurements, such as magnetic or electromagnetic systems, to detect disturbances created by targets of interest. For small targets such as ordnance, the associated disturbances are usually small and require extremely close measurement spacing. Airborne surveys using point measurement systems are ineffective because navigation cannot typically support the precision sampling that is needed. Detailed ground surveys of large areas are prohibitively expensive.

\subsubsection{Large Area Reconnaissance}

A second advantage of complete ground coverage is illustrated by Figure 8 , which shows two thermal images of an anomaly detected at the NODA site. These images were obtained as by-products of the ordnance survey but illustrate a feature of thermal imaging that could be applicable to reconnaissance site characterization over large areas. The anomaly in Figure 8 stands out clearly from background because of its size (about $20 \times 30 \mathrm{ft}$ ) and shape. It is believed to be associated with a chemical disposal area. The advantage provided by a thermal imaging system is simple: anomalies of this nature could simply not be missed.

For thermal imaging to be truly useful for reconnaissance characterization surveys, more work must be done to determine what types of characterization targets produce thermal anomalies. As described in Appendix A, there is reason "n doubt that buried waste of any kind will be detectable by a thermal system. The anomaly in Figure 8, though, suggests that the Martin Marietta system may still be a viable technology for finding certain types of surface contamination.

\subsection{Limitations of the Thermal Technology}

\subsubsection{Surface Object (Ordnance) Detection}

Time of day can significantly limit the effectiveness of the thermal system for detecting objects on the ground surface. During nonoptimal periods of the diurnal cycle, ordnance are not distinguishable from the clutter produced by rocks and sagebrush, as shown by the NODA examples in Figure 9. Rocks and sagebrush are prevalent at NODA and impose a stern challenge for a thermal detection system because they produce anomalies that can be similar to ordnance in amplitude, size, and shape. Unless flight times are selected to provide high contrast, there are no criteria for 


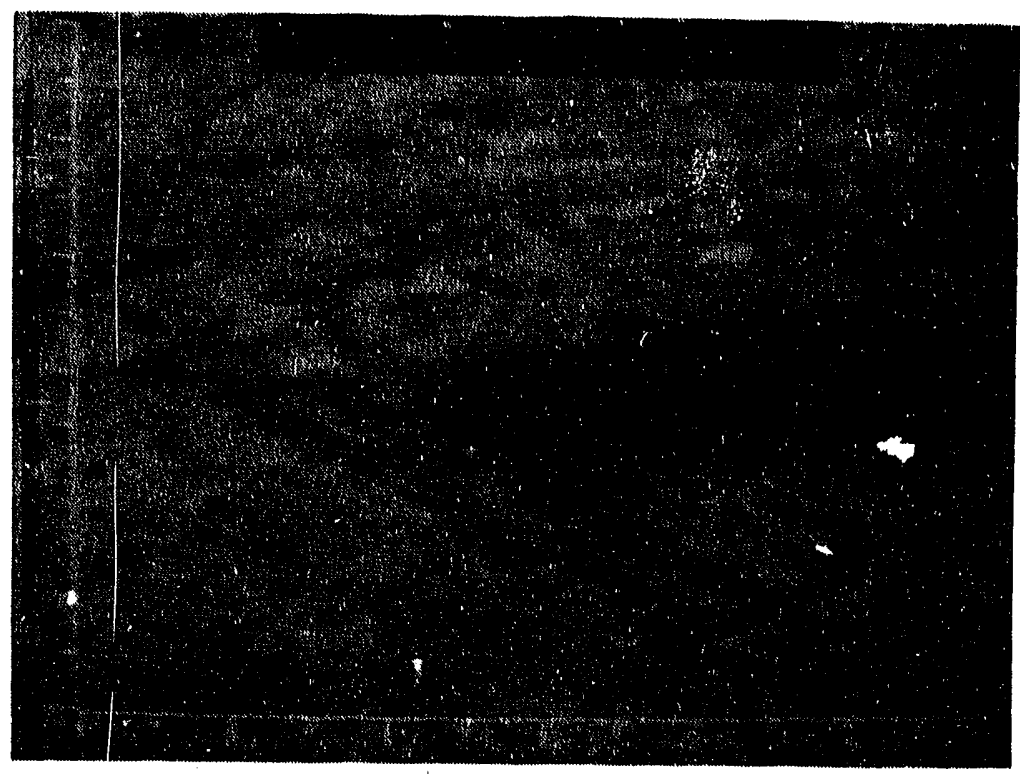

(a) NODA - 9 October 1991 - 9:30 p.m.

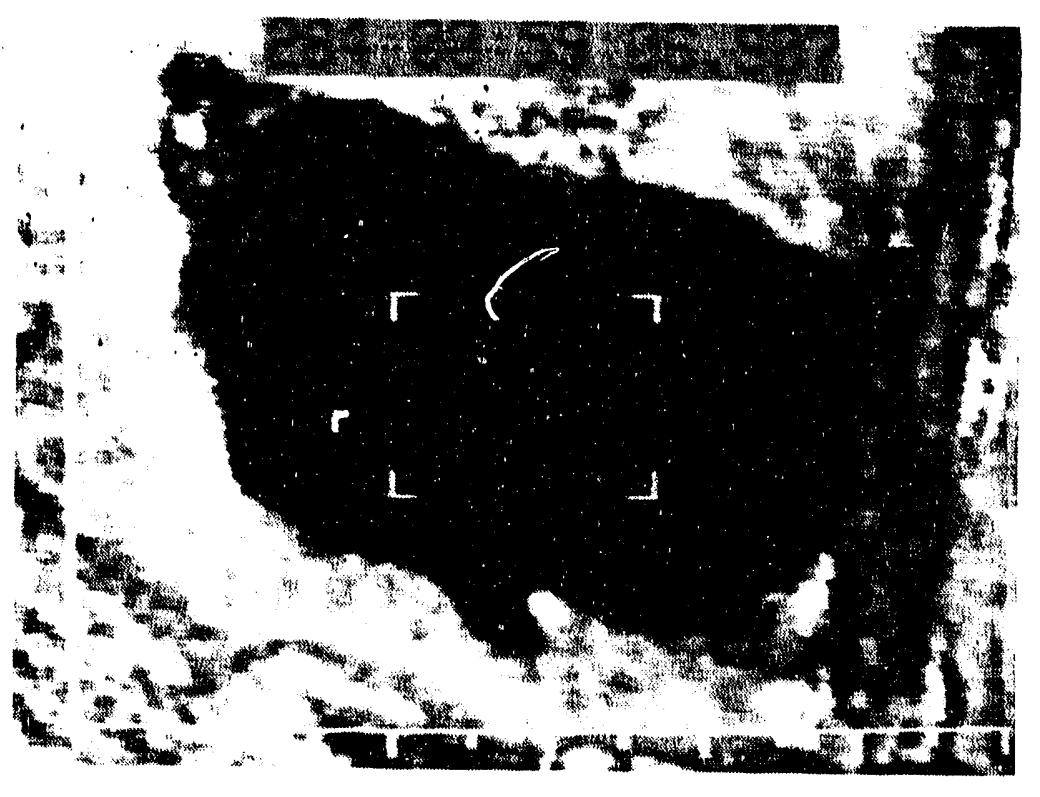

(b) NODA - 11 October 1991 - 1:00 a.m.

Figure 8. Oblique (a) and overhead (b) image of a thermal anomaly at the NODA site. The anomaly is believed to be associated with a chemical disposal area and is being investigated. The airborne thermal system is uniquely suited for mapping thermal anomalies of this type over large search areas where spills or other surface contamination are suspected. (Anomaly size is about $20 \times 30 \mathrm{ft}$.) 


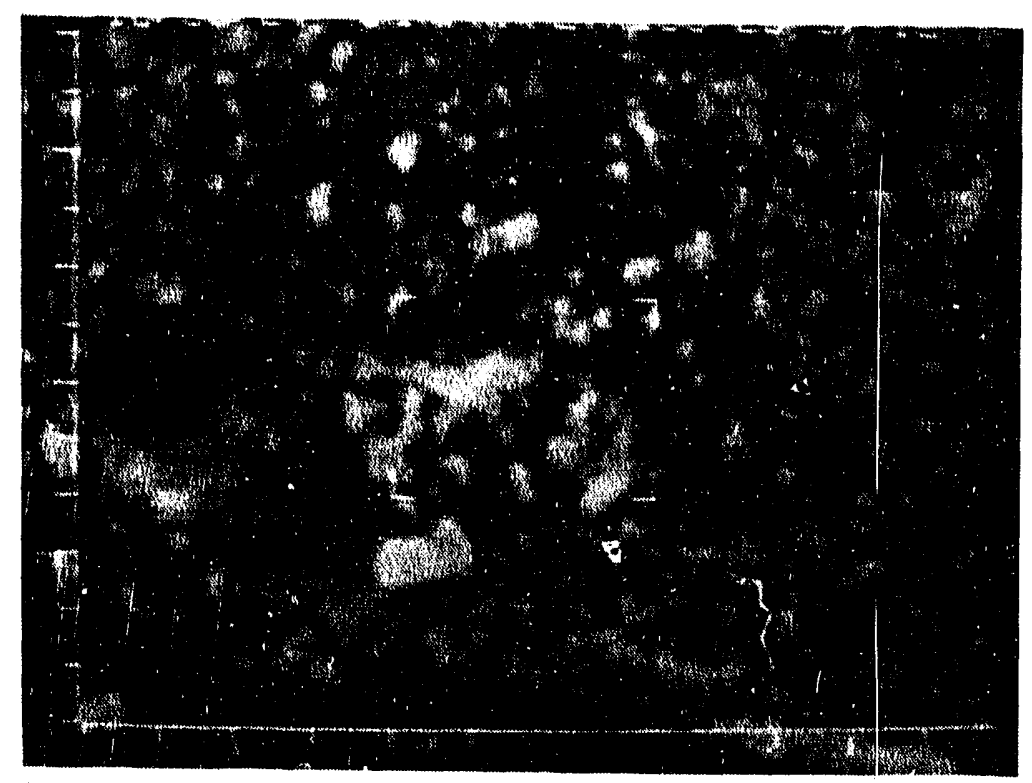

(a) NODA - 9 October 1991 - 2:00 p.m.

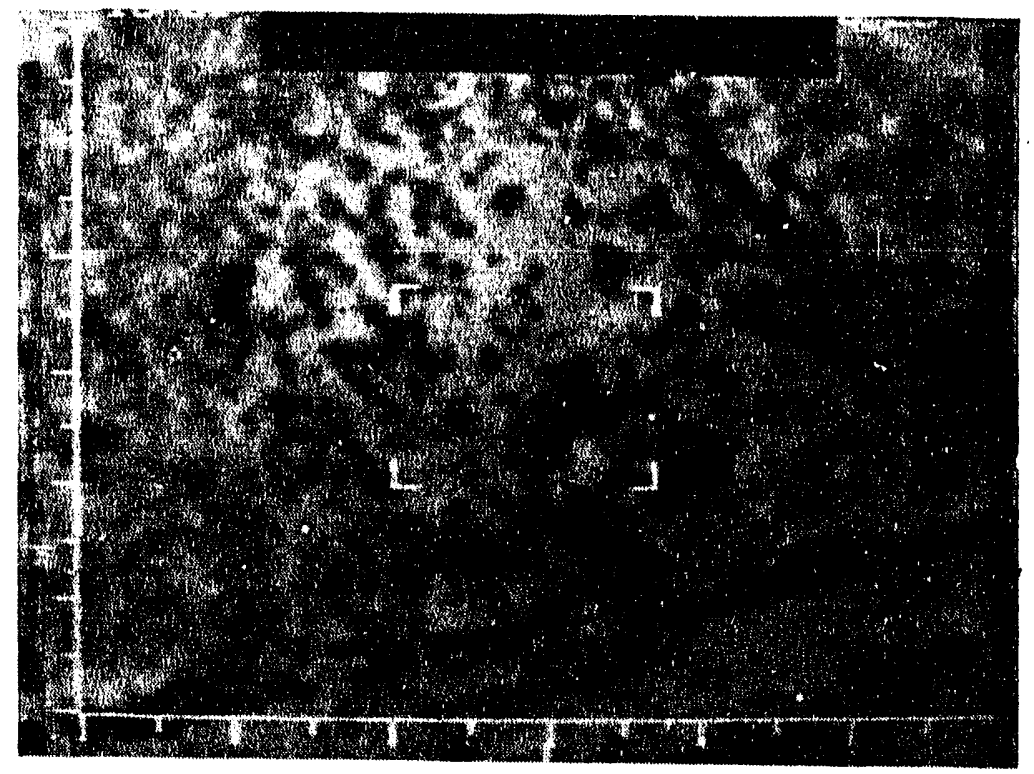

(b) NODA - 9 October 1991 - 9:00 p.m.

Figure 9. Thermal images of NODA site illustrating the influence of time of day on the clarity of thermal anomalies. The upper image (a) was taken in full afternoon sun. The lower image (b) of the same area was taken at night. Note how the relative temperatures of the ground, sagebrush and ordnance differ in the two images. This effect will also depend on the time of year and weather. 
distinguishing targets from clutter, either by manual interpretation methods or using the automated image processor. The time window for thermal mapping is therefore rigidly restricted to those times when temperature differentials are present.

Although rocks and sagebrush may be unique to the IINEL, they illustrate the most important consideration for evaluating thermal methods or other remote sensing methods. Some means for distinguishing signals of interest is needed. When criteria for making these distinctions cannot be found, results will always be ambiguous. For the thermal case, the criteria may relate to anomaly amplitude, shape, or size and will depend on specific conditions such as the nature of the vegetation, the weather, or the time of day. The whole process requires an appreciation of the principles that govern thermal imaging, relevant properties of the survey targets, and properties of naturally occurring features that will generate the background clutter.

\subsubsection{Burled Waste Detection}

The Martin Marietta system was ineffective for characterizing buried waste. This conclusion is based on two observations: (a) all of the thermal anomalies observed over the buried waste sites correlated with surface phenomena such as vegetation, ground topography, or soil texture and (b) the thermal anomaly pattern observed at the Cold Test Pit had no apparent relationship to the known distribution of objects in the pit. The thermal images shown in Figure 10a, from SDA Pit 9, and Figure 11a, from the SL-1 burial site, show several large area temperature anomalies. Since there are no strict criteria for recognizing anomalies due to buried waste, the thermal features at Pit 9 might be attributed to waste on the basis of size and general appearance. The size, shape, and orientation of the thermal features observed at SL-1 suggest that these anomalies might be caused by the burial trenches. Figures $10 \mathrm{~b}$ and $11 \mathrm{~b}$ are standard (visible spectrum) photographs of the same areas. By comparing the thermal and visible images, it becomes apparent that each major thermal anomaly has a counterpart in the visible spectrum. The visible counterparts, which can be interpreted easily, show that the anomalies are the result of differences in vegetation and/or ground subsidence.

Figure 12a is a thermal image of the Cold Test Pit. Again, by comparing this image with the visible image in Figure 12b, it is apparent that all the major features of the thermal image have a counterpart in the visible spectrum. The anomalies may be straightforwardly interpreted. The left side pit boundary anomaly corresponds with a change in soil texture, probably generated by a grading operation. The vertical striping pattern corresponds with furrows on the ground surface, also from a grading operation. The truncated " $U$ " shaped anomaly at the top of Figure 12a corresponds with a raised earth berm surrounding the borrow pit immediately north of the Cold Test Pit. No other anomalies are apparent, even in locations where known waste occurs within several feet of the ground surface (compare with Figure 5). 


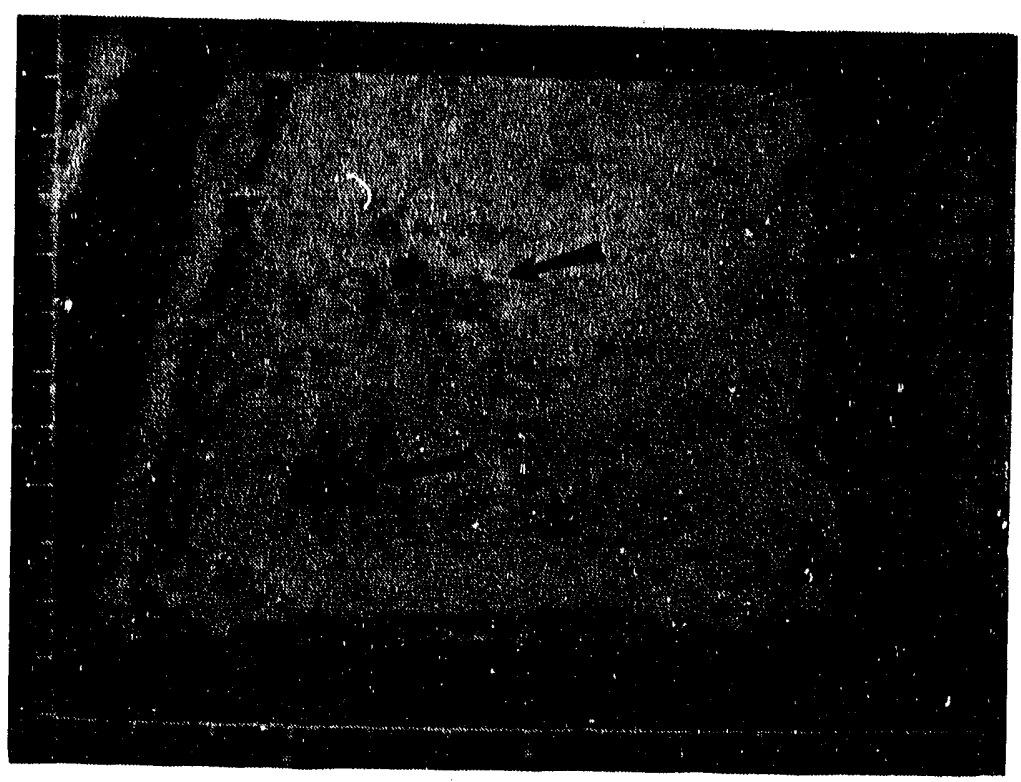

(a) SDA Pit 9 - 14 October 1991 - 9:15 p.m.

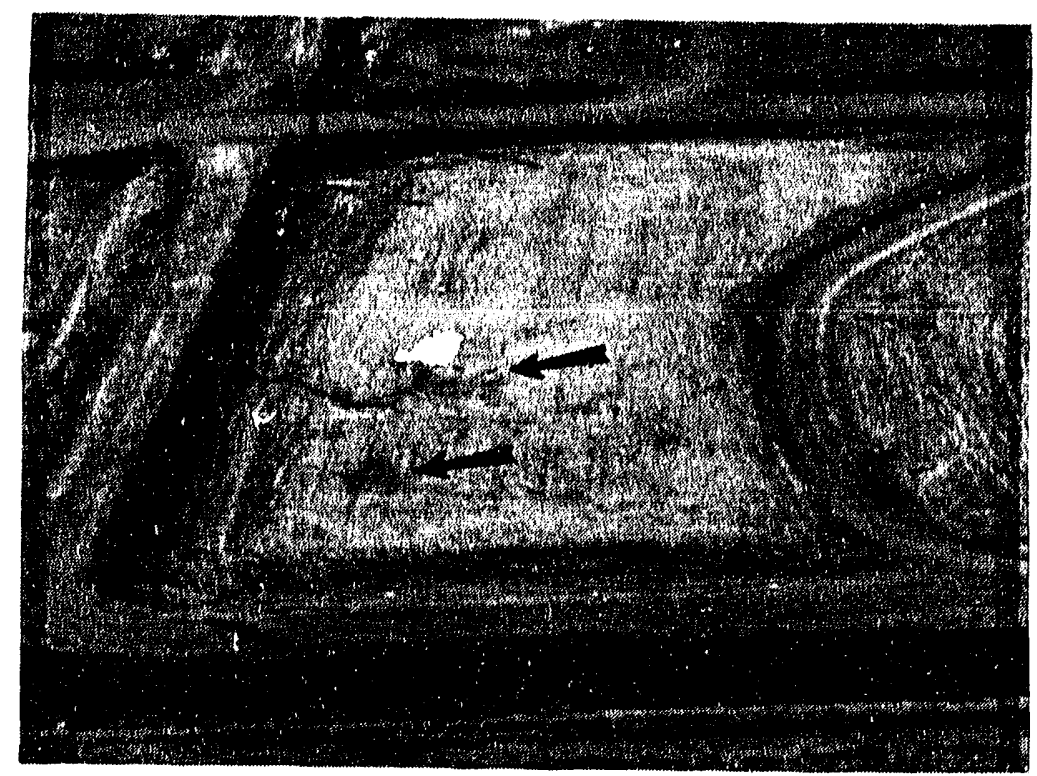

(b) SDA Pit 9 - visual spectrum

Figure 10. Thermal image (a) and visual spectrum image (b) of a portion of Pit 9 at the SDA (see Figure 4 for location). The faint thermal anomalies visible in (a) (shown by arrows) appear to correspond with changes in vegetation visible in (b). Note the strong anomalies produced by the roads and roadside vegetation. At an uncontrolled site, these features must somehow be distinguished from anomalies of interest. 


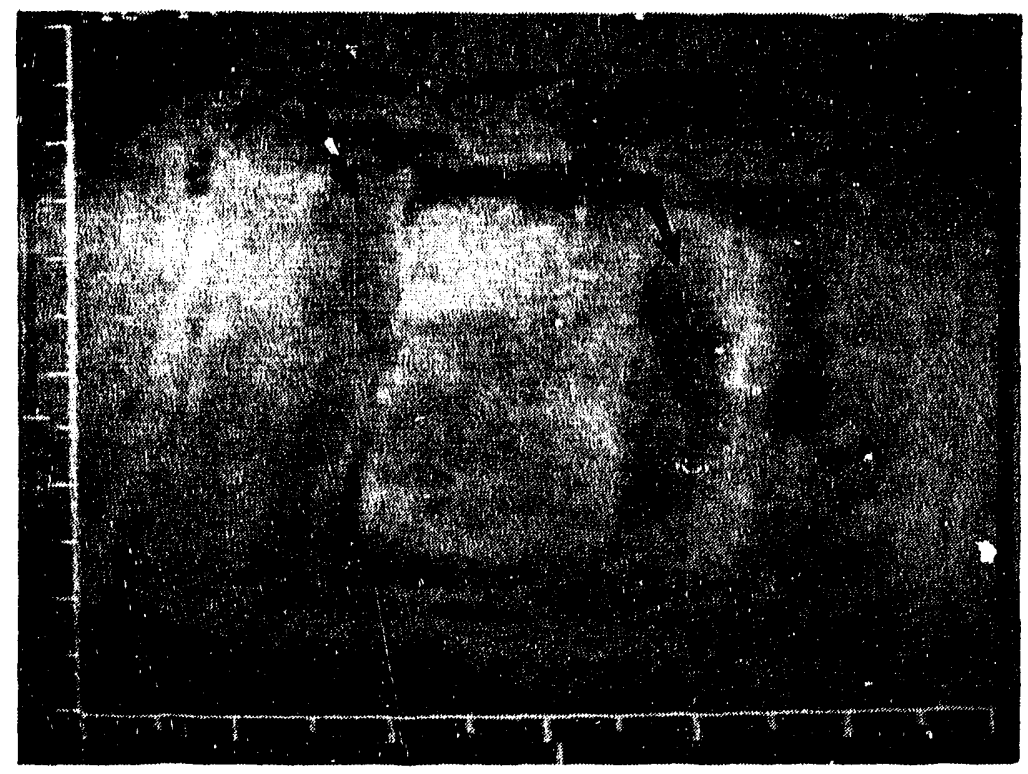

(a) SL-1 - 16 October $1991-1: 17$ a.m.

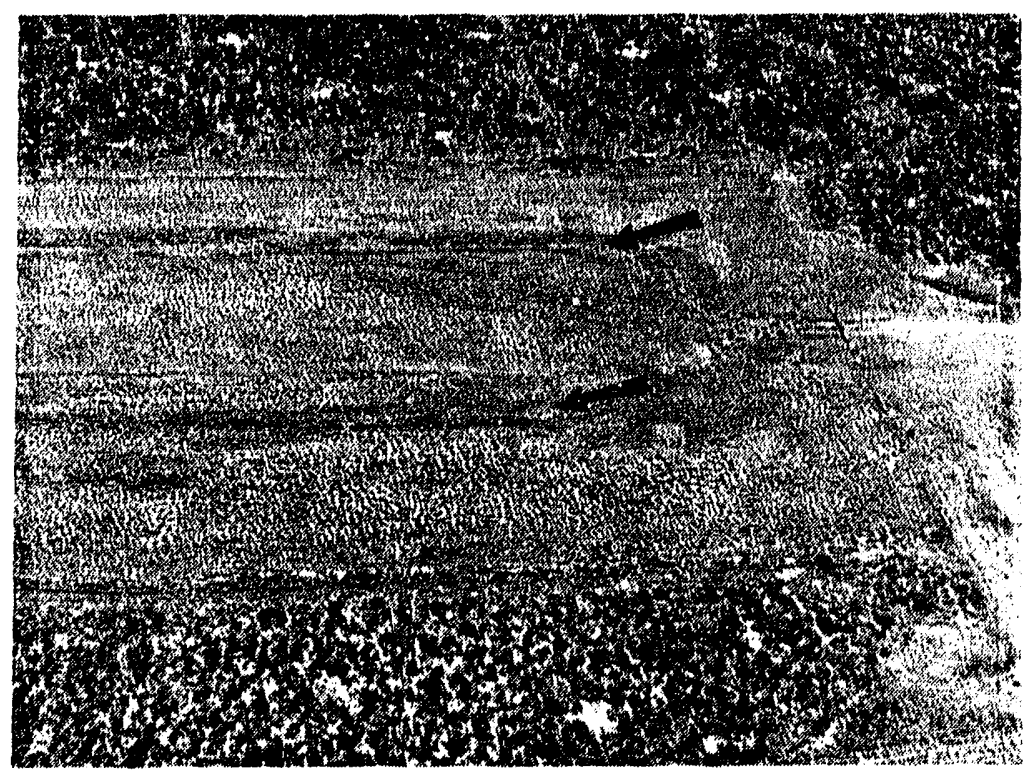

(b) SL-1 - visual spectrum (side view)

Figure 11. Thermal image (a) and visual spectrum image (b) of the SL-1 burial area showing clear anomalies (shown by arrows) associated with two waste disposal trenches. It is apparent that vegetation and soil conditions produce thermal anomalies that may be difficult to distinguish from effects caused by buried objects. 


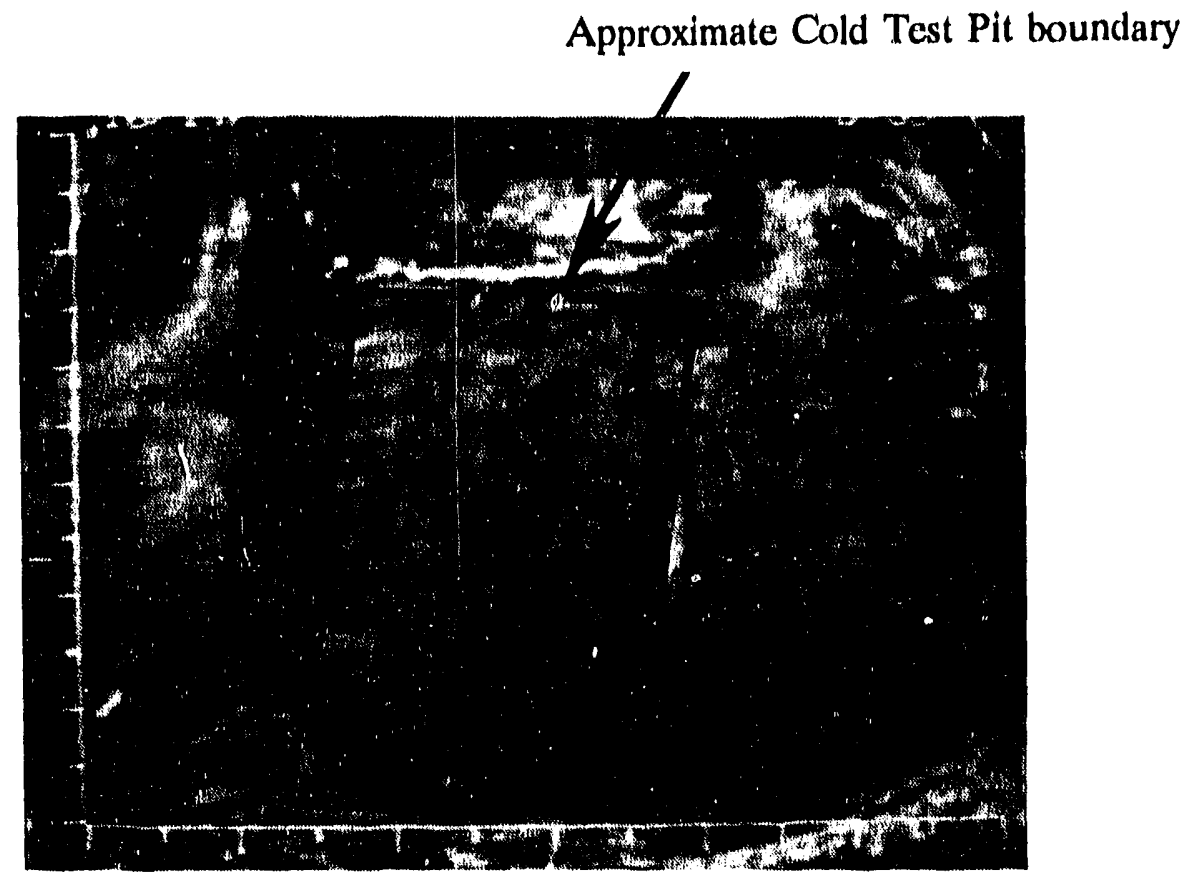

(a) Cold Test Pit - 15 October 1991 - 1:45 p.m.

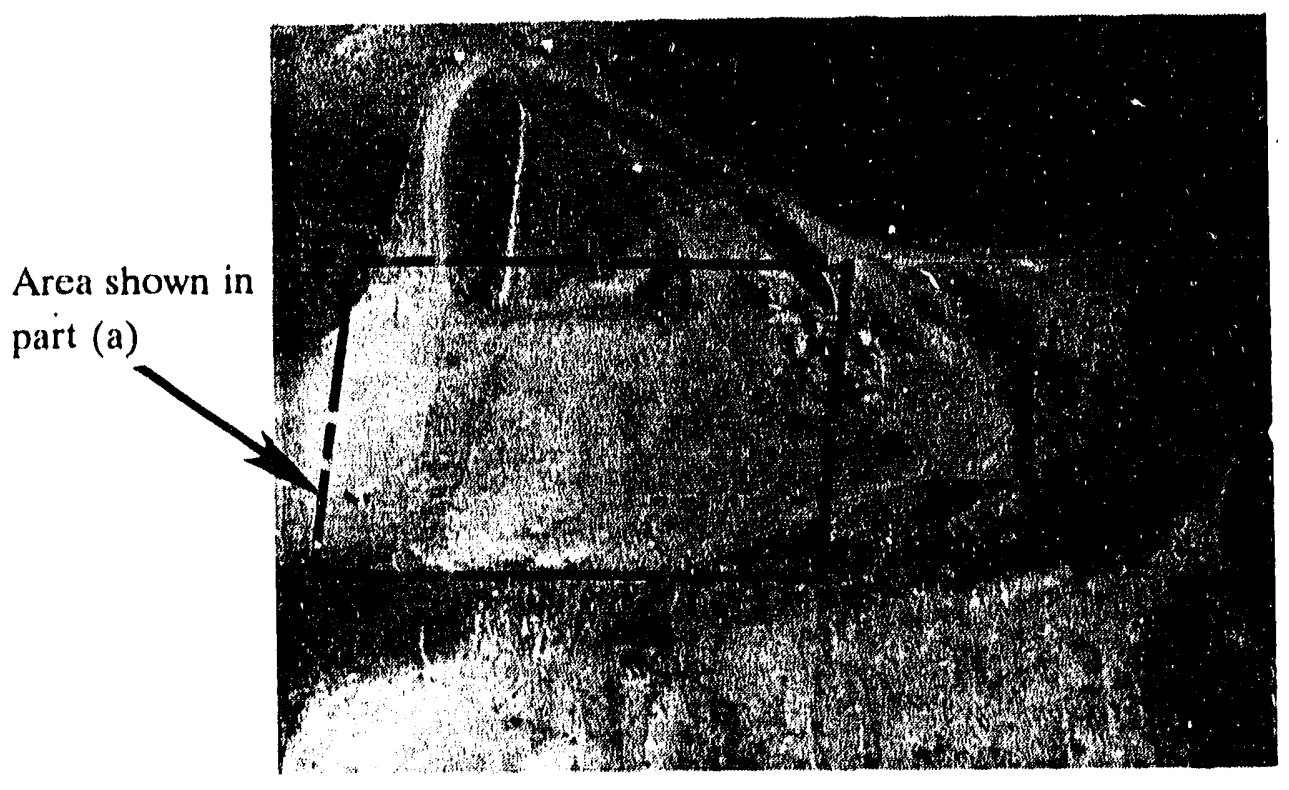

(b) Cold Test Pit - visual spectrum

Figure 12. Thermal image (a) and visual spectrum image (b) of Cold Test Pit. Several anomalies suggest that topography also influences the thermal condition of the ground. The faint vertical stripe anomalies (central area of pit) correspond with ground furrows from recent grading operations. The borrow pit and encircling berm (top boundary of pit) also show up as thermal anomalies. Note time of day. 
Vegetation changes and disturbed soil areas may be indirect indicators of waste burial operations. Because of this fact, thermal maps showing such features may be useful for waste site characterization. However, it would appear that visual aerial photography may be equally or more useful for this purpose.

\subsubsection{Thermal Theory}

The Martin Marietta effort at the INEL suffered because of poor theoretical foundation. Predictions made by Martin Marietta concerning the thermal effects of buried waste (Martin Marietta, 1992) were not confirmed by the results of the INEL survey. These predictions were based on questionable assumptions and oversimplified models. More sophisticated calculations made by EG\&G Idaho suggest that the thermal signature of buried objects becomes vanishingly small below depths of 1 or $2 \mathrm{ft}$ (Appendix A). Some consensus must be reached on the subject of buried object detectability.

The Martin Marietta and EG?:G Idaho modelling efforts focused on the question of detectability limits. The theoretical computati ons depended on various assumed values including the thermal properties of soils and buried matırials and the magnitude of the natural thermal gradient in the shallow soil zone. Figure 13 schem itically illustrates a second consideration relating to the problem of detectability that is not so strongly dependent on assumptions about material or environmental properties. If thermal anomalies are produced by buried objects, they will doubtless have much smaller amplitudes and longer spatial wavelengths than anomalies generated by features on the ground surface (such as rocks or vegetation). Except in completely barren terrain, the thermal images recorded by a Martin Marietta type system will contain a superposition of shallow and deep effects. Interpretation of these data may be a difficult anomaly separation problem.

\subsection{Recommended Developments}

The following are recommendations for further development of the Martin Marietta airborne thermal imaging system. These recommendations reflect the opinion that the current thermal system can be a very effective tool for locating ordnance or other surface debris within large search areas. They also reflect the opinion that the capabilities of the current system for site characterization are limited to detecting chemical spills or similar surface phenomena. The limited applicability to buried waste characterization appears to be the result of fundamental limitations, but the topic may warrant further theoretical study. 


\subsubsection{Navigation System}

A system for referencing the thermal imagery to a standard ground coordinate system is needed. Without this capability, it will be difficult to locate objects or areas of interest that are detected by the thermal system. In addition, the current navigation system should be modified or replaced with a system that can position the aircraft over a target area and perform a $100 \%$ ground coverage survey without the need for ground-based navigational aids. The need for ground-based markers or personnel may restrict access to certain areas.

\subsubsection{Visible Spectrum Recorder}

Visible spectrum data should be recorded along with the infrared spectrum data whenever the system is flown during daylight. A capability for collecting visible spectrum data will increase the effectiveness of the thermal system by providing a means to evaluate ground clutter anomalies. It could also be useful for developing site basemaps and for detecting ground or vegetation disturbances during portions of the diurnal cycle where thermal data are of limited value.

\subsubsection{Sound Theoretical Basis for Buried Waste Applications}

A sound theoretical basis is needed to justify further investment in thermal systems for buried waste applications. Realistic three dimensional thermal modeling systems are available and should be used. At a minimum, this work should

1. Address the effects of soil type and moisture content

2. Determine valid thermal parameters for common waste types such as fluid filled barrels, soil vaults, and diffused chemical contamination

3. Examine the depth of diurnal solar influence

4. Examine the annual variations of the shallow thermal gradient in natural systems. 


\section{Hypothetical thermal anomalies}

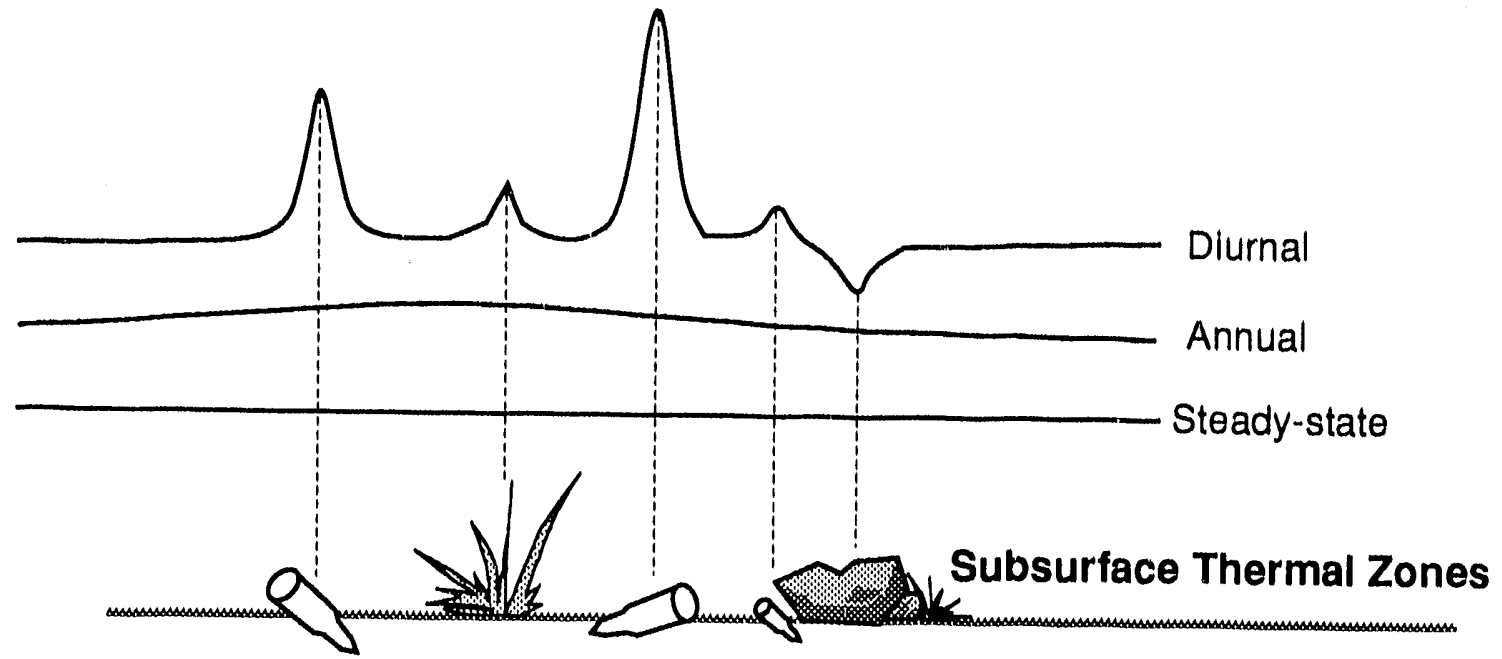

Diurnal Zone: subject to daily cycles of warming and cooling from sun; extends from surface to depths of $1-2$ feet.

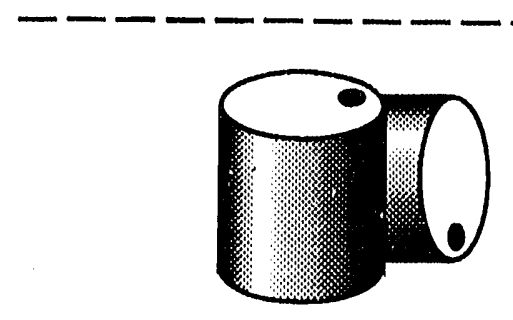

Annual Zone: subject to gradual warming and cooling with changing seasons. This zone may extend to substantial depths if bedrock has high permeability. Most buried waste. occurs within this zone.

Steady-state Zone: temperature changes little over time; possible influence from long term climate changes, major shifts in groundwater flow, or magmatic activity; in some settings, may occur as shallow as 8 - 10 feet.

Figure 13. Schematic illustration showing subsurface zones categorized according to the dominant thermal influence. Diurnal solar energy does not penetrate beneath the first few feet. Thus, thermal anomalies created by typical buried waste must have a fundamentally different origin than the anomalies created by metallic objects on the surface. Any temperature differentials that do exist within the Annual Zone must be conducted through the insulating soil overburden. Here, they become superimposed on the much stronger anomalies originating in the Diurnal Zone. 


\section{EBASCO MAGNETIC AND ELECTROMAGNETIC SURVEY SYSTEM}

The EBASCO geophysical surveying system is based on standard magnetic and electromagnetic (EM) surveying methodology. Magnetic and EM methods were originally developed for mineral and petroleum exploration, but have been adapted for numerous other applications. They are now probably the most widely used geophysical tools for waste site characterization.

Magnetic sensors measure disturbances in the earth's natural magnetic field caused by the presence of ferrous materials. The interaction between static magnetic fields (such as the earth's field) and ferrous materials in the ground is governed by fairly simple physical laws, making interpretation of magnetic data somewhat less complicated than for some of the other geophysical methods. A number of rock types are magnetic, especially crystalline rocks like basalt. The magnetic properties of rocks are variable and unpredictable. Only a few manmade materials are magnetic (mainly iron and steel), but these materials are strongly magnetic compared to natural materials. Thus, anomalies due to iron or steel objects are easy to recognize. For most metallic objects of interest in waste site investigations, the amplitude of a magnetic anomaly is directly proportional to the amount of ferrous material present, and inversely proportional to the square or cube of the distance between the object and the magnetic sensor.

The EBASCO EM system is based on electromagnetic induction. An inductive EM system uses a transmitter to radiate a low frequency electromagnetic field into the ground. This primary field induces eddy currents in subsurface conductive materials. The eddy currents create a secondary magnetic field that is measured by a i'eceiver coil. The amplitude and phase of the secondary magnetic field are related to the distribution of conductive materials in the ground. The EM method is less selective than the magnetic method since most metals, soils, and rock are conductive. As in the magnetic case, metals have much higher conductivities than most natural materials, and their anomalies are usually easy to recognize. However, the interaction between multiple conductors in the subsurface can create complex anomaly patterns that are difficult to interpret. The depth of investigation for EM induction methods depends on the strength and frequency of the primary field and the subsurface conductivity.

\subsection{Equipment Description}

The Aerospatiale 315B (Lama) helicopter, navigation system, magnetic sensors, electromagnetic sensors, and data logging equipment for the EBASCO survey were supplied by Aerodat, Ltd. and Rocky Mountain Helicopters. 
The magnetic sensor array consists of four optically pumped total field magnetometers. The array is suspended from the underside of the helicopter on a $100 \mathrm{ft}$ tow cable (see Figure 14). In addition to providing four independent measurements of the total magnetic field, the sensor configuration allows the horizontal and vertical gradients of the magnetic field to be calculated. During survey operations, magnetic data from each of the sensors is recorded digitally at $5 \mathrm{~Hz}$. (The sensor array flown by EBASCO at the INEL also incorporated a three component vector magnetometer. However, these data were not compiled and will not be discussed further in this report.)

As shown in Figure 15, the EM sensor array consists of five transmitter-receiver coil pairs operating at different frequencies. The EM system includes three horizontal coplanar coil systems operating at $500 \mathrm{~Hz}, 4175 \mathrm{~Hz}$, and $33000 \mathrm{~Hz}$, and two vertical coaxial coil systems operating at 935 $\mathrm{Hz}$ and $4600 \mathrm{~Hz}$. As with the magnetic sensors, the EM sensors are suspended from the helicopter on a $100 \mathrm{ft}$ tow cable. The transmitter - receiver separation of the coil pairs is $7 \mathrm{~m}$. Both quadrature and inphase components of the EM response from each coil pair are recorded digitally at a sample rate of $10 \mathrm{~Hz}$.

\subsection{Navigation}

Several navigation systems were employed for the INEL airborne survey. A Motorola Miniranger IV computed aircraft position continuously using range information from two radio transponders in the INEL vicinity. The Miniranger system produced the most reliable navigation data, and these data were used to locate the magnetic and EM data collected during the EBASCO surveys. The sensor housings were outfitted with GPS antennas, allowing sensor position to be derived independently of aircraft position. As was the case for the Martin Marietta GPS system, in-flight GPS data were unreliable due to inadequate satellite coverage. GPS was only used to establish tie points for each survey area. The tie point data were acquired by hovering the helicopter above specified ground locations. Additionally, down-looking video cameras were mounted in both the helicopter and on the sensor housings. These cameras monitored the position of the sensors with respect to the helicopter and provided an image of the ground along the flight path. The video cameras were used as backup systems only since there were not enough visible landmarks to do precise navigation. The helicopter was also equippeci with three independent altimeter systems. These were used during operations to monitor and adjust ground clearance, and were used in post-processing as a means to identify anomalies caused by changes in sensor elevation. 


\section{Tow Cable Connected to Helicopter 100' Above}

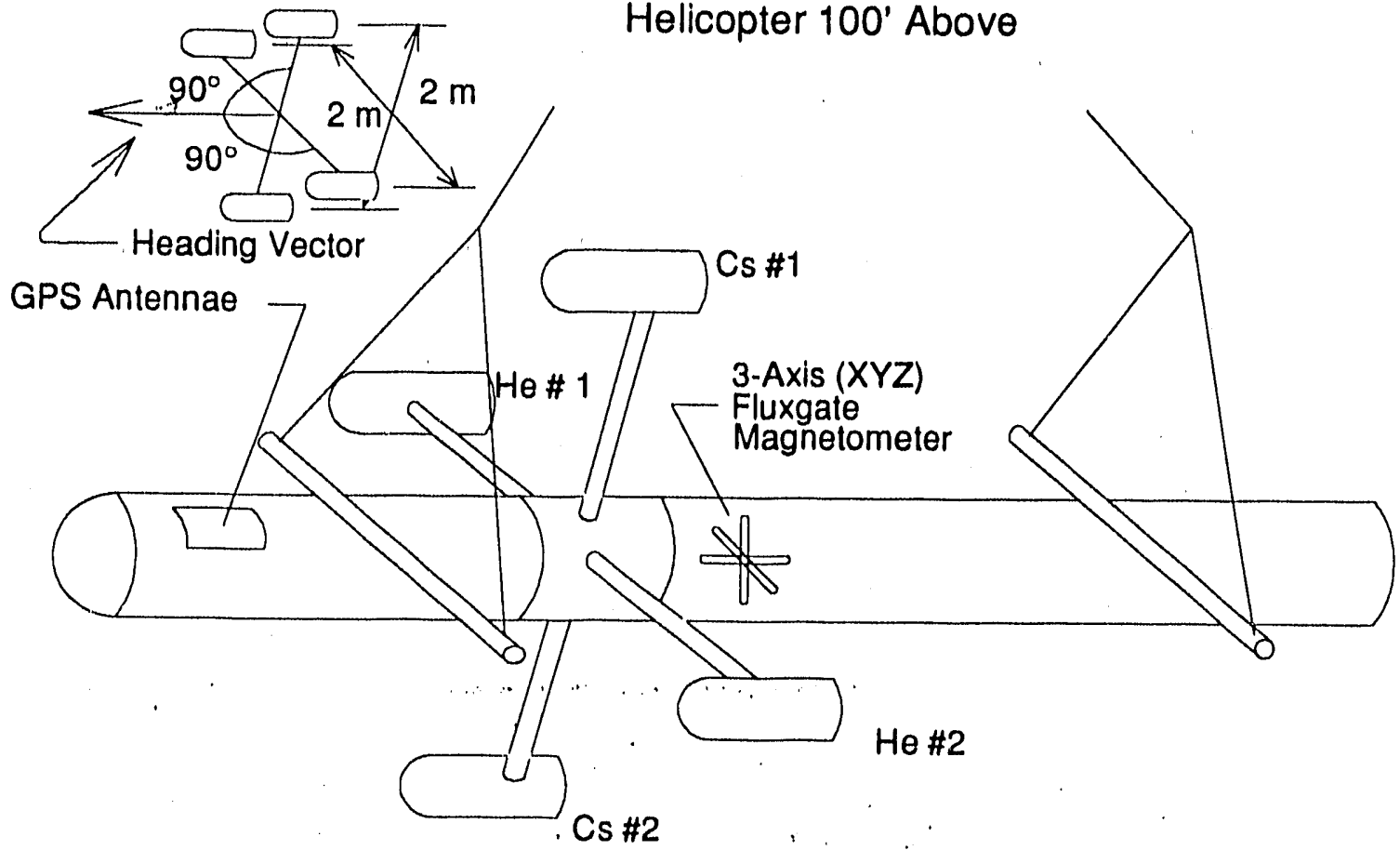

Magnetic Sensor Information

\begin{tabular}{|c|l|c|c|}
\hline Sensor & \multicolumn{1}{|c|}{ Description } & $\begin{array}{c}\text { Separation } \\
\text { Distance }\end{array}$ & Gradient Calculation \\
\hline Cs\#1, Cs\#2 & $\begin{array}{l}\text { Optically pumped Cesium } \\
\text { magnetometers; measure } \\
\text { total magnetic field. }\end{array}$ & 2 meters & VG $=($ Cs\#1 - Cs\#2)/2 \\
\hline He\#1, He\#2 & $\begin{array}{l}\text { Optically pumped Helium } \\
\text { magnetometers; measure } \\
\text { total magnetic field. }\end{array}$ & 2 meters & $\begin{array}{c}\text { Horizontal Gradient } \\
\mathrm{HG}=(\text { He\#1 }- \text { He\#2)/2 } \\
\text { (sign adjusted for traverse direction) }\end{array}$ \\
\hline
\end{tabular}

Figure 14. Schematic drawing and description of the EBASCO magnetic sensor array used for the INEL survey. Note that the vertical gradient and horizontal gradient calculations are dependent on the heading and tilt of the sensor housing. 


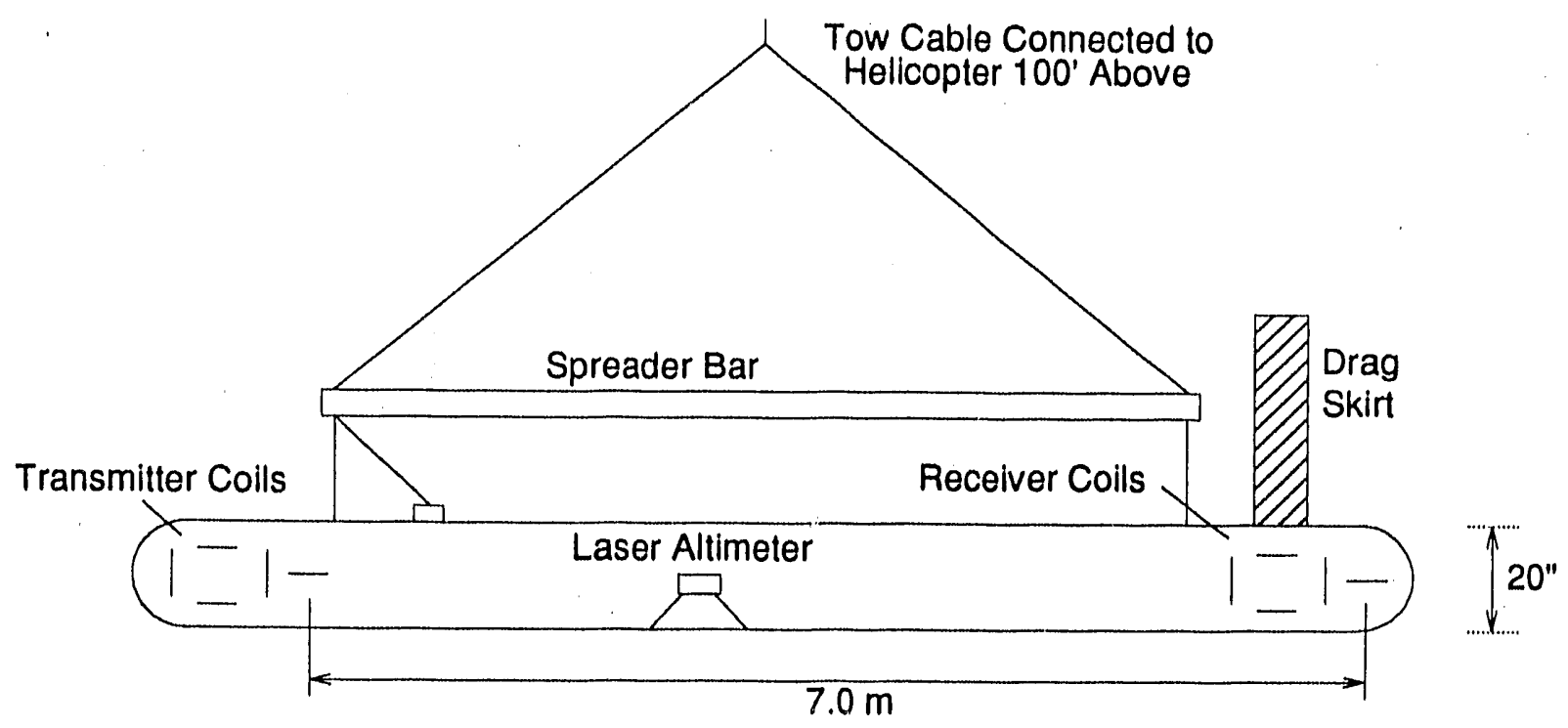

EM Sensor Information

\begin{tabular}{|c|c|c|c|}
\hline Coil Pair & $\begin{array}{c}\text { Operation } \\
\text { Frequency }(\mathrm{Hz})\end{array}$ & Orientátion & $\begin{array}{c}\text { Skin Depth } \\
\text { (feet) }\end{array}$ \\
\hline 1 & 500 & Horizontal Coplanar & 425 \\
\hline 2 & 935 & Vertical Coaxial & 310 \\
\hline 3 & 4175 & Horizontal Coplanar & 150 \\
\hline 4 & 4600 & Vertical Coaxial & 140 \\
\hline 5 & 33000 & Horizontal Coplanar & 50 \\
\hline
\end{tabular}

Figure 15. Schematic drawing and description of the EBASCO electromagnetic sensor array used for the INEL survey. The skin depth is a commonly used indicator of the exploration depth for inductive electromagnetic systems. 


\subsection{Data Analysis}

Coordinates for the magnetic and electromagnetic data points are calculated based on time data recorded in both the sensor and navigation data files. The position of the data points is interpolated based on the two closest helicopter positions (determined by the time of collection) recorded by the navigation system. The magnetic data are then corrected for diurnal variations, and the vertical and horizontal gradients are calculated. The EM data require correction for coil spacing fluctuations caused by temperature changes. After corrections, maps of magnetic total field, vertical gradient, and horizontal gradient are produced directly. The EM quadrature and inphase data are converted into phase angle data. Phase maps are then produced for each of the five frequencies.

\subsection{EBASCO Survey}

EBASCO acquired airborne geophysical data at the four INEL sites between October 21 to November 13, 1991. Magnetic and EM data were acquired separately to avoid interaction between the systems and to accommodate the need for different sensor elevations. The magnetic data were collected along flight lines spaced an average of $20-\mathrm{ft}$ apart, with sensors at a nominal elevation of 15- $\mathrm{ft}$ above ground level. The EM data were acquired along similar flight paths but with a sensor elevation of about 45-ft above ground level. In addition, Cold Test Pit data were collected a second time using an average flight line spacing of $10 \mathrm{ft}$.

The EBASCO surveys generated a huge volume of data: three magnetic data sets (total field, horizontal gradient, and vertical gradient) and $10 \mathrm{EM}$ data sets (quadrature and inphase components at five frequencies) for each of the four survey sites. Map compilation was a substantial undertaking and was not fully completed at the time this document was being prepared. In particular, the EM data were not available in a conventional format in time to be fully incorporated into this analysis. However, all the data were previewed during a visit to EBASCO during January 1992, and a general assessment of the utility of the various data sets was made at that time.

The following discussion focuses on general aspects of the geophysical survey. Most of the specific examples cite the magnetic data. Little can be said concerning the EM data except that it is clearly a lower resolution tool as deployed for this demonstration. This is due largely to the $45 \mathrm{ft}$ sensor elevation. A more complete analysis of the EM data is unlikely to substantially alter the main points of this evaluation. 


\subsection{Demonstrated Capabilities}

\subsubsection{Pit and Trench Boundary Mapping}

Figure 16 shows magnetic vertical gradient data for a portion of the SDA occupied by narrow, parallel waste burial trenches (see Figure 4 for location). Anomalies in the data indicate that significant quantities of ferrous metallic waste are scattered throughout the trenches. The alignment of anomalies along parallel linear bands is a typical indicator of burial trenches. The portion of the SDA covered by the Figure 16 map has eight separate trenches with centerlines spaced 15 to 50 -ft apart. The vertical gradient anomalies have the same trend as the trenches, but only five separate anomalies are resolved, spaced 30- to $60-\mathrm{ft}$ apart. The most likely cause for this discrepancy is inaccurate navigation. EBASCO estimates that the absolute coordinates for the magnetic data may be mislocated by 50 to $100 \mathrm{ft}$ (EBASCO, 1992). The GPS system used to establish the local datum for the SDA survey site is believed to be the ultimate source of error. Because of the error magnitude, it is not possible to confidently compare the magnetic data against mapped trench locations as a means to judge the system's resolution.

Within the context of DOE objectives for site characterization, two significant capabilities can be stated. First, large burial pits containing ferrous metallic waste could be easily located by an airborne system when only broad search areas are known. Second, once a burial area is discovered, the size of the burial site and the arrangement of pits and trenches at the site can be roughly determined. For magnetic sensors, these capabilities depend on having a wide distribution of ferrous metallic waste. EM sensors increase the effectiveness of the system since a wider variety of waste forms can be detected.

\subsubsection{Large Area Reconnaissance}

A segment of magnetic horizontal gradient data near the center of the NODA site is shown in Figure 17. The dominant anomaly pattern consists of broad irregular magnetic highs and lows. Although not directly comparable with vertical gradient data, the pattern in Figure 17 is clearly different from the pattern observed over the SDA trenches. These anomalies are associated with basalt, which forms bedrock beneath the thin soil overburden at NODA. The anomaly patterns 


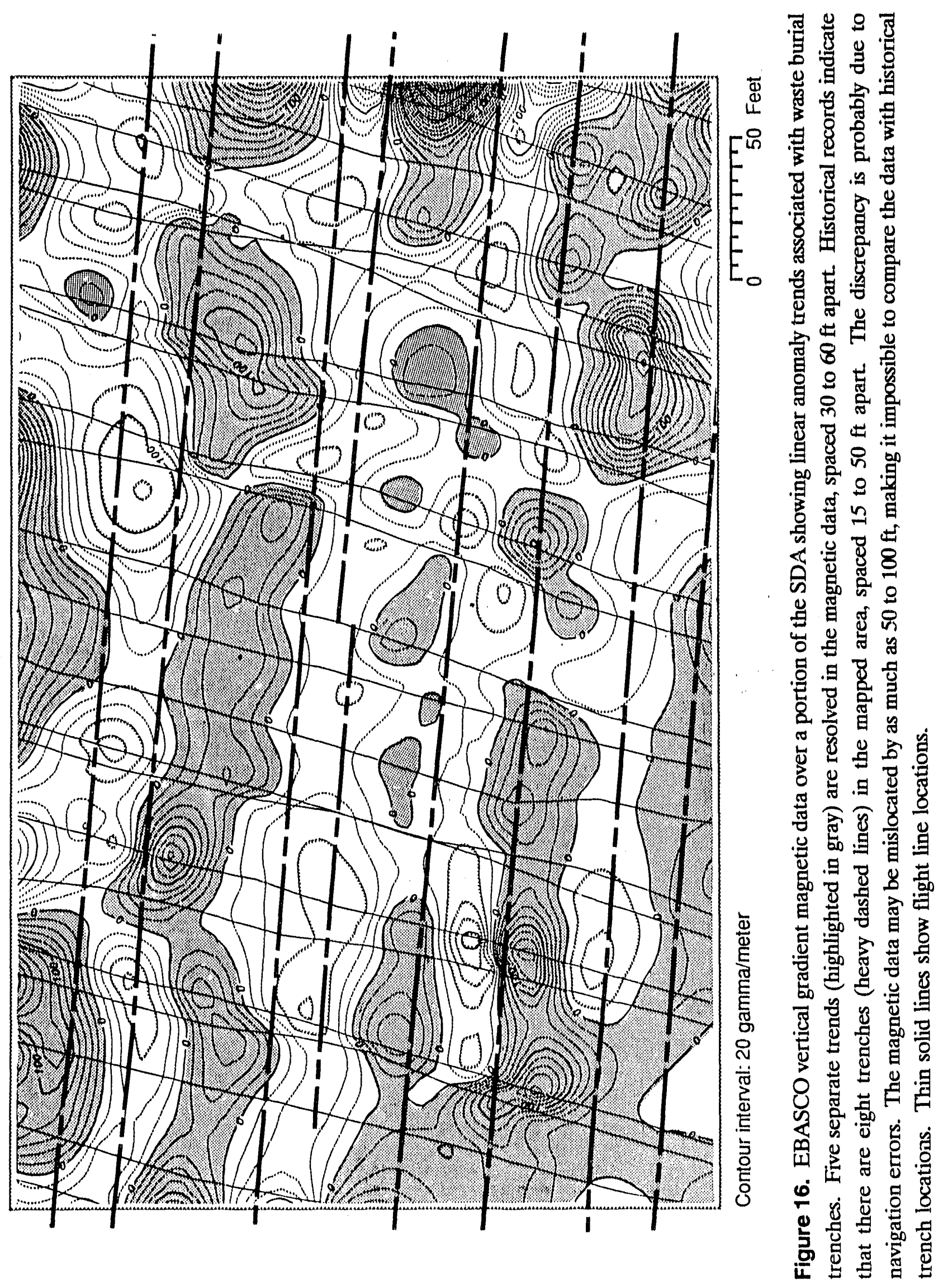




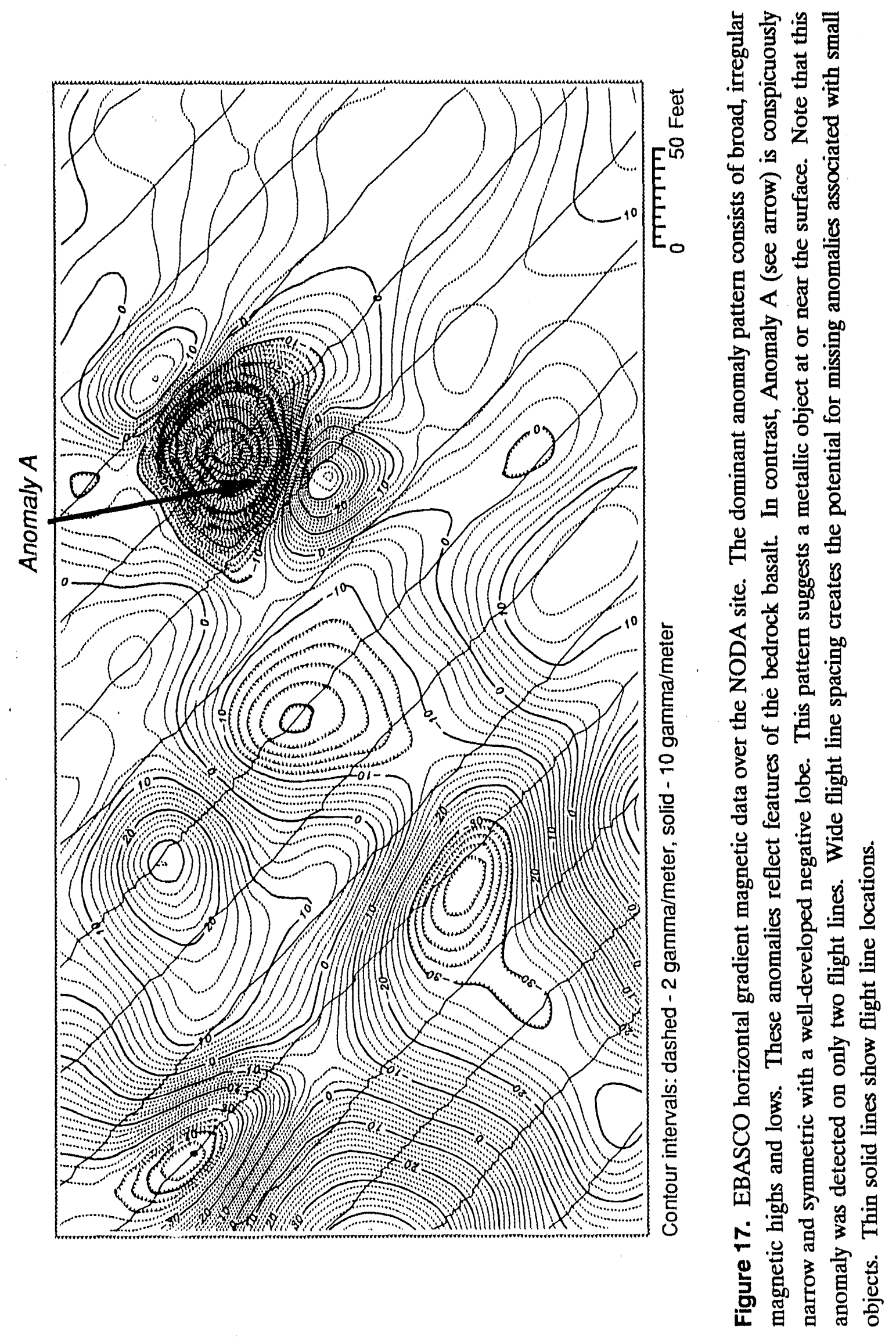


reflect $t \mathrm{l}$. distribution of discrete basalt flows, the bedrock topography, or possible faults or other structures in the basalt. One exception to the general anomaly pattern occurs near the center of the map area (see arrow). Here, a conspicuously narrow and symmetric anomaly with a well-developed negative lobe suggests a small metallic object at or near the ground surface. At present, the actual source of this anomaly is unknown.

Figure 18 shows magnetic vertical gradient data (a) and EM quadrature data (b) at the Cold Test Pit. The magnetic data show both sharp, high amplitude anomalies from metallic objects buried in the Cold Test Pit and broad background anomalies associated with basalt. The EM data in (b) illustrate the usefulness of collecting complementary data sets. On the basis of magnetic data alone, the distinction between anomalies due to waste and those due to basalt is not always clear. The EM data, which in this case respond almost exclusively to buried waste, can be used to make this distinction.

The examples from NODA and the Cold Test Pit illustrate another, perhaps more significant, capability of the EBASCO airborne geophysical system. Aside from the ability to locate buried waste, magnetic and EM data can provide information on subsurface geology. In areas such as the INEL, where bedrock contains magnetic constituents, magnetic data can be used to interpret depth to bedrock or the locations of faults. Although not demonstrated by the INEL surveys, EM data has been used successfully in some environments to map groundwater and subsurface stratigraphy. Geologic and hydrologic information of this type can contribute significantly to regional site investigations since groundwater and the controls on groundwater flow bear directly on the movement of contaminants in the subsurface. It is well known that geophysical data can sometimes address these issues, but proper data are rarely collected due to the high cost of land based geophysical surveying. Airborne surveys are ideally suited for this purpose.

\subsection{Limitations of Airborne Geophysical Technology}

The primary limitation of the EBASCO airborne system is its relatively poor resolution compared with typical ground surveys. The consequences of low resolution are that (a) pit boundary and object locations are very rough, (b) detailed delineation of objects within a waste mass is not possible, and (c) small objects may be completely missed. These limitations are all stated relative to the performance of ground surveys. This difference is clearly depicted in Figure 19, which compares the EBASCO magnetic vertical gradient data with vertical gradient data collected on the ground at the Cold Test Pit. Interestingly enough, the resolution limitations attributed to the airborne data are often stated for ground-based surveys as well. Indeed the objectives for buried waste characterization are driving geophysical methodology in the direction of higher and higher resolution. Although the EBASCO work must be considered a high resolution airborne survey, resolution is not a particular strength of airborne data collection. 


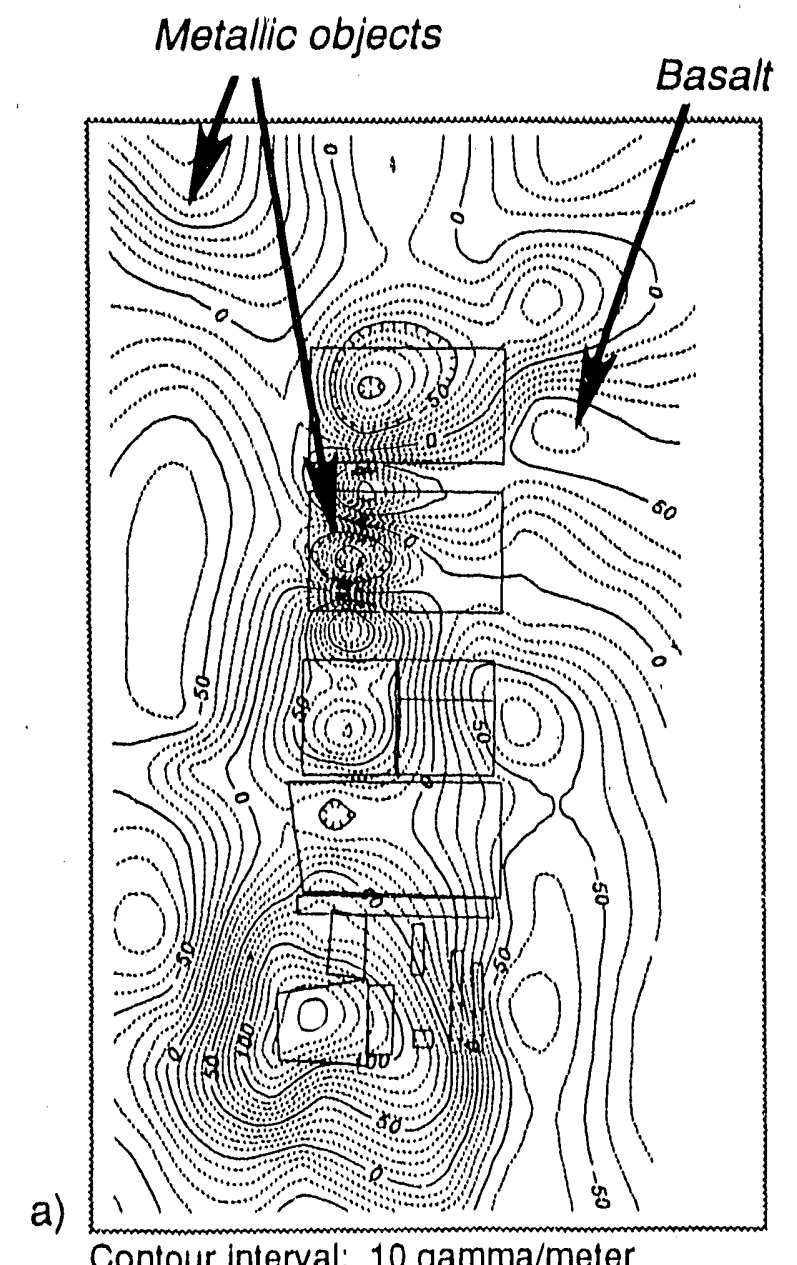

Contour interval: 10 gamma/meter
Metallic objects

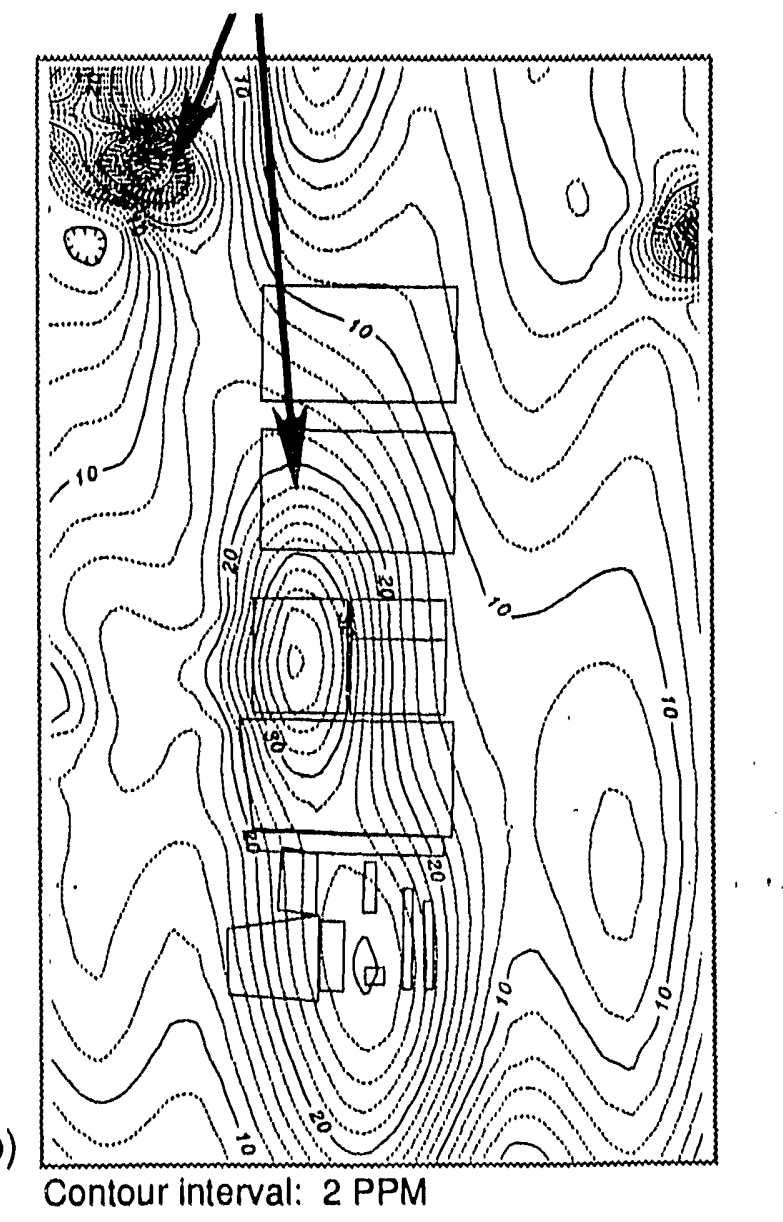

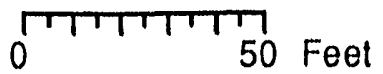

Figure 18. EBASCO vertical gradient magnetic data (a) and electromagnetic data (b) over the Cold Test Pit. The electromagnetic data are inphase data for the $4600 \mathrm{~Hz}$ coil pair. The basalt magnetic anomaly can be distinguished from metallic waste magnetic anomalies by the lack of corresponding electromagnetic signature. The strong anomalies in the upper left portion of the maps are caused by a crane that was parked near the Cold Test Pit during the survey. Outlines show locations of Cold Test Pit materials (see Figure 5). 


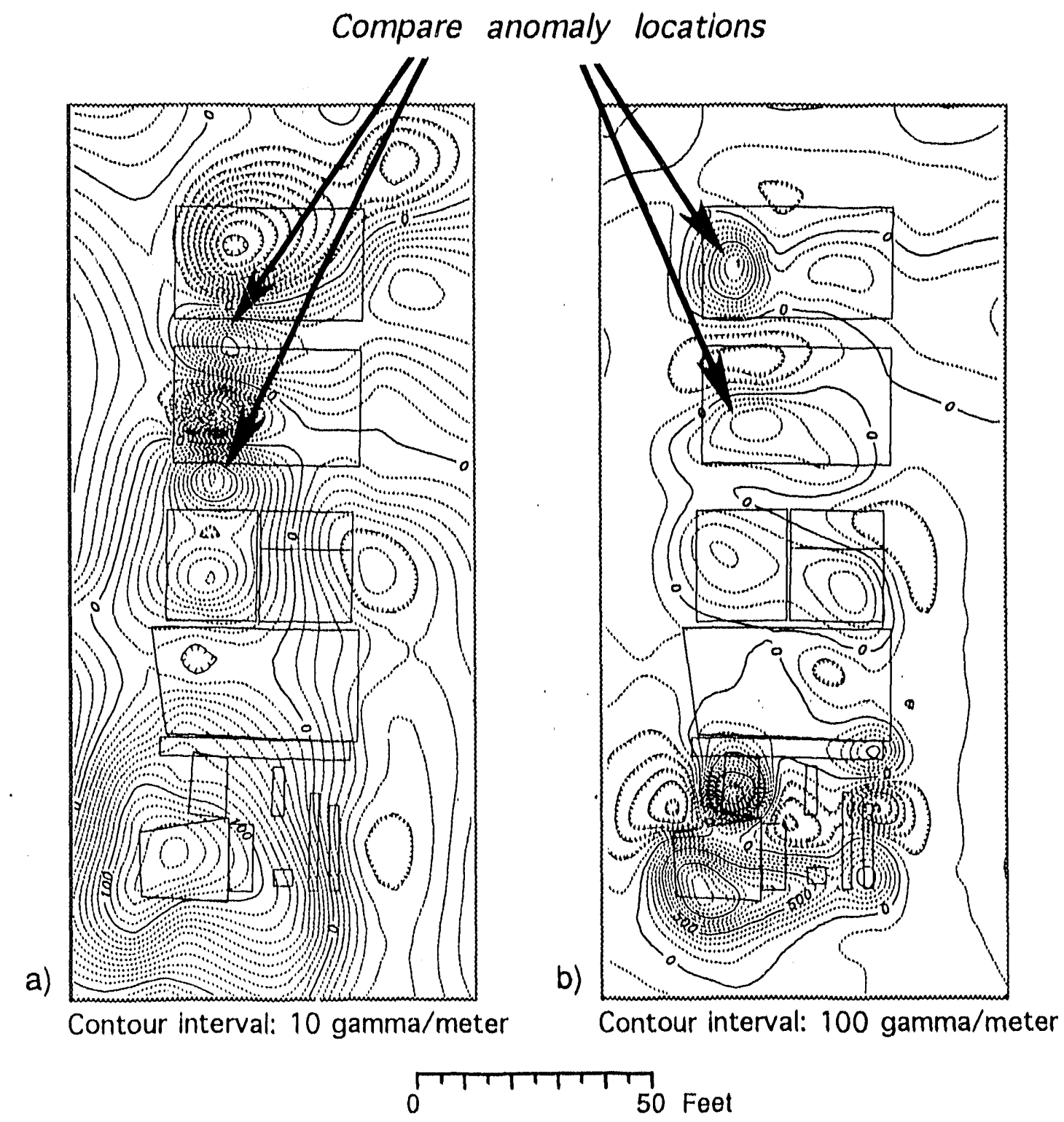

Figure 19. Comparison of vertical gradient magnetic data collected by the EBASCO airborne system (a) and by conventional ground-based surveying (b) at the Cold Test Pit. Anomalies in the EBASCO data are broader and have much lower amplitudes than in the conventional data. This is due to the difference in sensor elevation (15 versus $1.5 \mathrm{ft}$ ). Also, portions of the EBASCO data are distorted due to imprecise navigation (see arrows). Precise navigation becomes extremely important for small area surveys. Note difference in contour interval. 
The major factors affecting anomaly resolution are discussed separately in the following sections.

\subsubsection{Data Spacing}

For airborne surveys, the spacing between data points along the flight path is a function of the flight speed and the time interval between successive sensor readings. For the INEL survey, the average data spacing along flight lines was about $5 \mathrm{ft}$, with sensors operating at their maximum sampling rate and the helicopter flying at the lowest stable speed. Spacing between adjacent flight lines varied, but $10 \mathrm{ft}$ was a practical lower limit. This limit was imposed by difficulties in precisely positioning and directing the aircraft using the Miniranger navigation system. Thus, the nominal grid for the airborne surveys was about $5 \times 10 \mathrm{ft}$. In Figure 20, the airborne grid is compared with the data spacing acquired during the Cold Test Pit ground survey.

Several observations can be made based on Figures 19 and 20. First, the airborne system is in no danger of completely missing the Cold Test Pit. The spatial sampling of the system is ideally suited for finding areas of about this size. It has, however, missed several relatively large objects buried within the pit, and it is not hard to see that it would have virtually no chance to methodically detect small scattered debris such as ordnance. A second point is that waste boundaries estimated using the airborne data will be severely biased by the flight line locations. When data spacing are inadequate to detect the full spatial distribution of anomalies, map data tend to become skewed and follow flight line trends.

\subsubsection{Sensor Elevation}

Sensor elevation strongly influences both the amplitude and shape of anomalies caused by shallowly buried waste. Higher sensor elevations cause anomalies to become broader and have lower amplitudes. This effect can be seen in the comparison between magnetic data sets at the Cold Test Pit shown in Figure 19. As the anomalies become broader, they tend to overlap and interfere with adjacent anomalies. This results in compound anomalies that are obscurely related to individual objects in the pit. A $15 \mathrm{ft}$ sensor elevation was the minimum achievable for the EBASCO INEL surveys because of the need to avoid fences and other structures located along the flight paths.

Figure 21 shows a more quantitative treatment of the sensor elevation effect. The two curves in this diagram are simulated anomalies computed for a steel casing model using a simple magnetic modelling program. The anomaly seen by the airborne sensor indicates only a single target. The anomaly seen by the ground sensor gives clear indications that two separate targets are present, Additionally, the anomaly amplitude has been severely attenuated at the higher elevation, and it is questionable whether it will be detectable at all in the presence of background noise. 


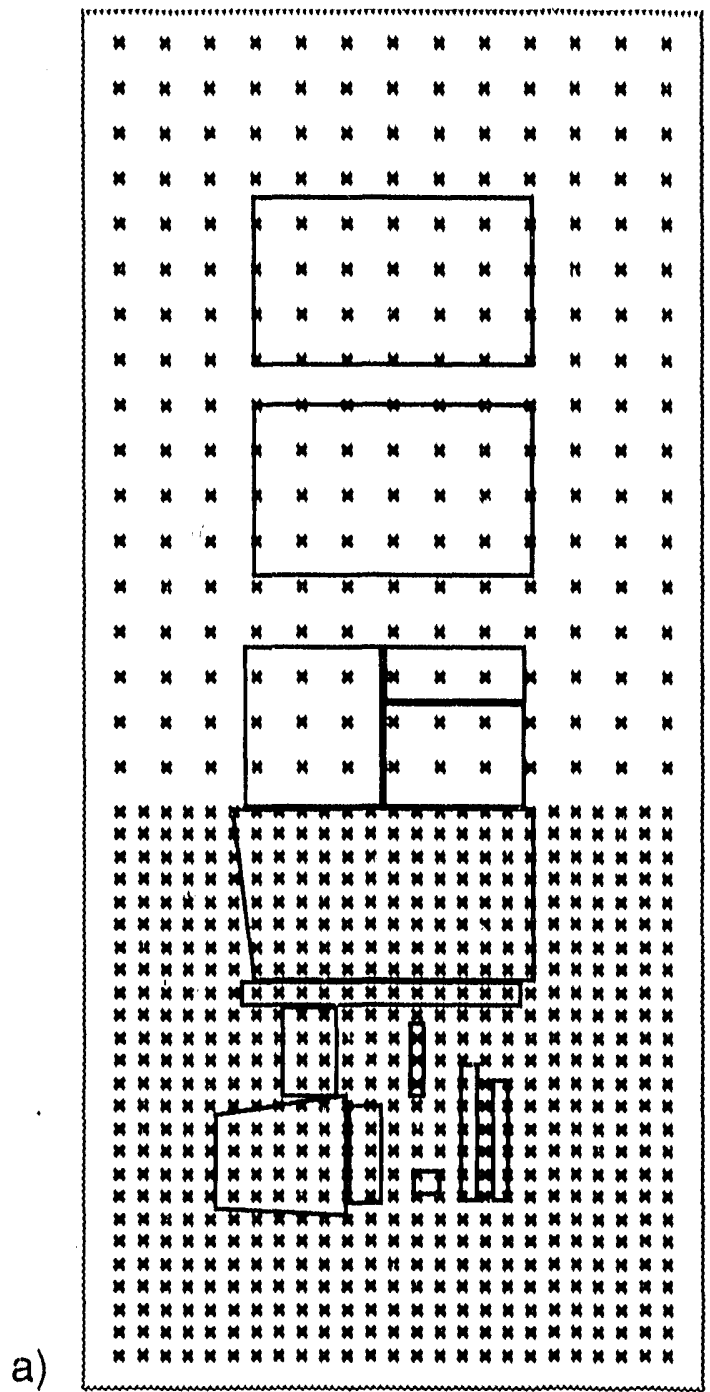

a)

b)
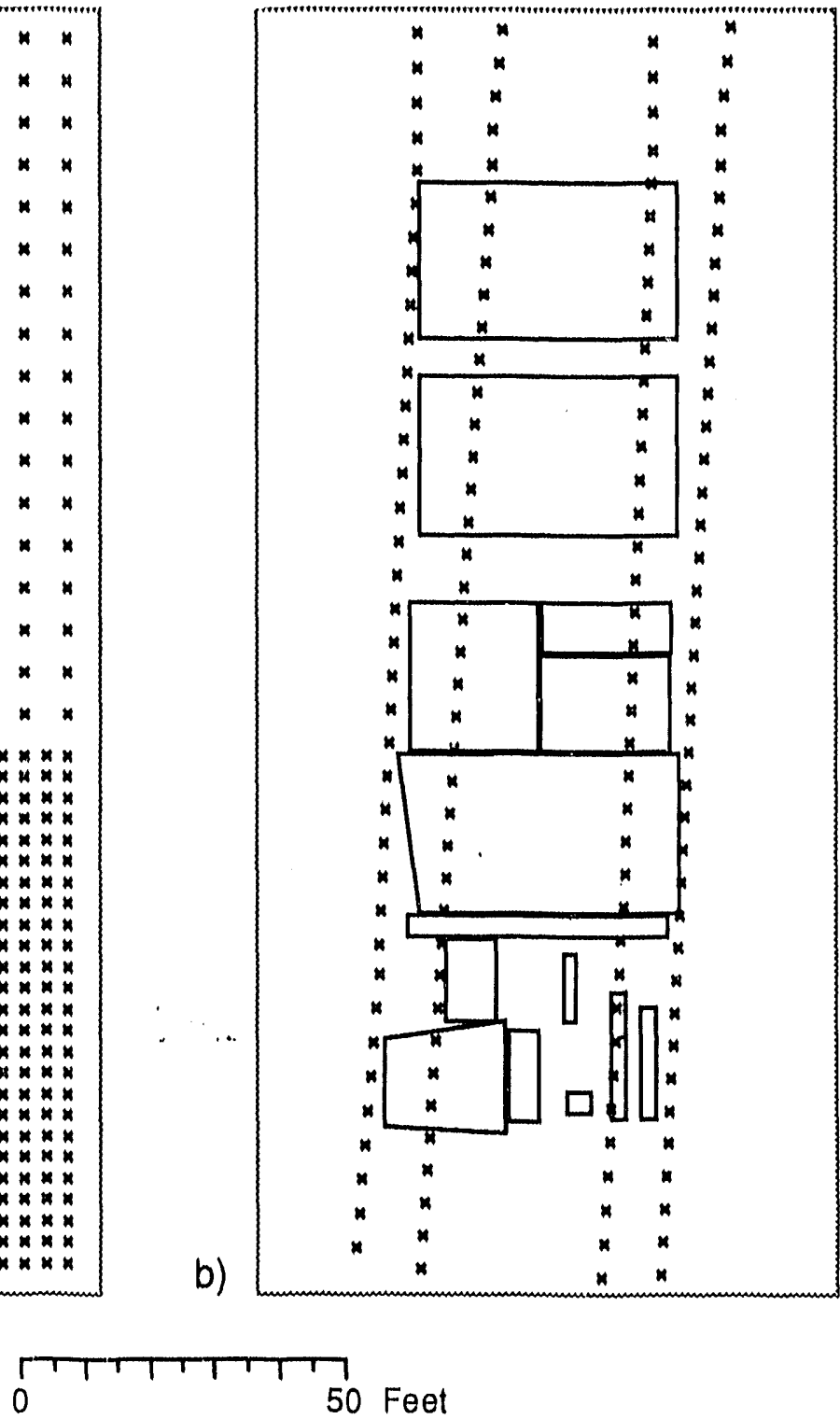

Figure 20. Comparison of data point density for conventional ground survey (a) and EBASCO airborne system (b). For aerial survey, data spacing along flight lines is limited by the aircraft speed and the sample rate of the sensors. Spacing between adjacent flight lines is limited by the precision of the navigation system. In conventional surveying, data spacing is limited only by labor costs. For large area surveys, the data density limitations of the airborne system are offset by the dramatic improvement in data acquisition rates. The ground survey data in (a) took about 8 hours to acquire. The airborne data was collected in about 10 minutes of flight time. 


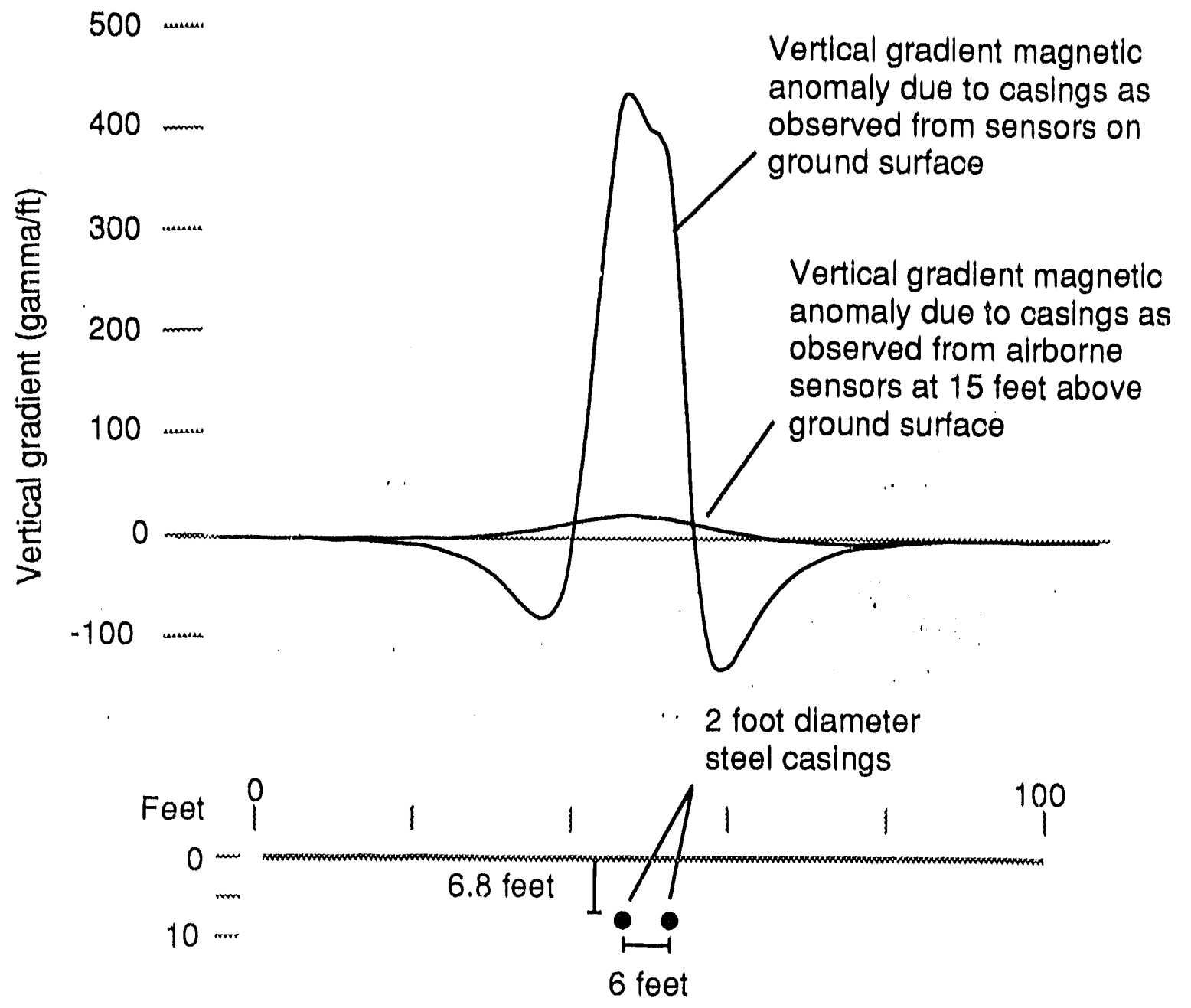

Figure 21. Magnetic model depicting the effects of sensor elevation for shallowly buried objects. The model is based on the depth and spacing of the $24 \mathrm{in}$. steel casings buried in the Large Object Zone of the Cold Test Pit. Magnetic anomalies (in this case, vertical gradient anomalies) become broader and have lower amplitudes as sensor elevation increases. Clearly, sensor elevation is a fundamental parameter affecting anomaly resolution. 


\subsubsection{Navigation}

The Miniranger navigation used by EBASCO is adequate for collecting reconnaissance data to locate unknown waste sites or to investigate site geology. The main shortcoming of this system arose during the conversion of the navigation data into position data based on a standard ground coordinate system. This conversion was never successfully accomplished, making it impossible to compare the geophysical data with cultural data such as the historic SDA pit boundaries, NODA roads, and the Cold Pit object boundaries. The capability to establish standard coordinates is an important requirement.

The navigation system is not accurate enough to support detailed mapping of pit and trench boundaries, delineate details of waste pits, or locate small isolated objects.

\subsubsection{Sensors}

The EBASCO maps of both the EM and magnetic data showed symptoms of "lag" related errors (Figures 22 and 23). Lag errors occur when data points are systematically mislocated from one flight line to the next. This shift can result from deficiencies in the clock system used to time stamp the geophysical data and the navigation data. It can also result from physical lag of the sensors behind the aircraft due to wind resistance. In this case, because the navigation system locates the aircraft instead of the sensors, systematic errors are introduced into the data locations. Lag errors contribute further uncertainty to an already questionable navigation system.

\subsection{Recommended Developments}

The following are recommendations for development of the EBASCO airborne geophysical system.

\subsubsection{Full Evaluation of EM Data}

The EM data that was collected by EBASCO unquestionably contain information that relates both to buried waste and subsurface geology. These data should be fully evaluated when they become available. The EM system used by EBASCO was particularly interesting because it was designed for multiple depths of investigation. Results of this evaluation should help determine the most effective sensors to use for DOE's purposes. 


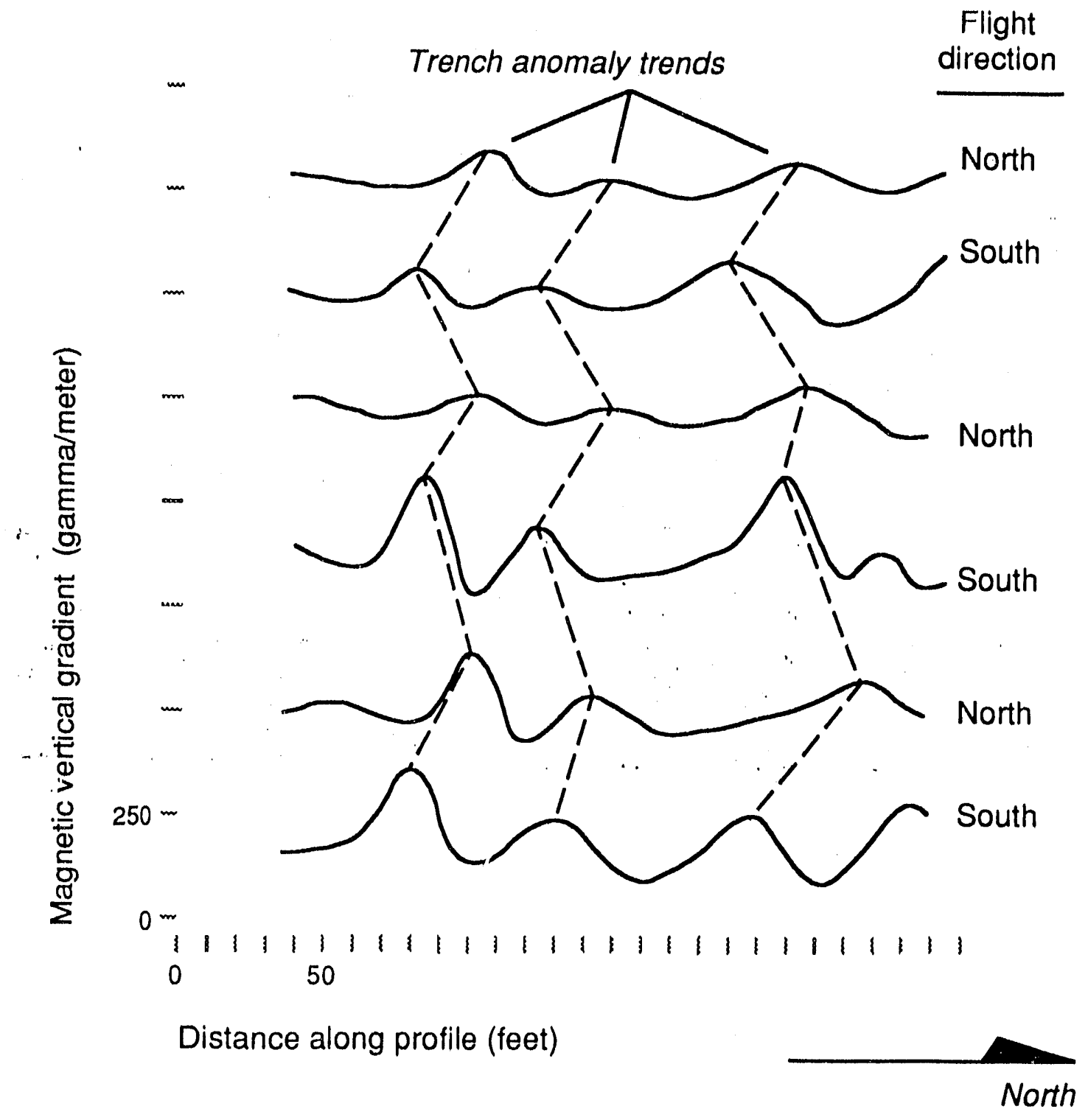

Figure 22. Vertical gradient profiles from EI'sASCO's survey of the SDA showing systematic offset of anomaly peaks. This lag effect is probably dive to air drag on the sensors, which causes them to trail behind the helicopter. The sense of off.set depends on the flight direction. The indicated lag is about $20 \mathrm{ft}$, which is enough to obscure anomaly trends due to narrow trenches. 


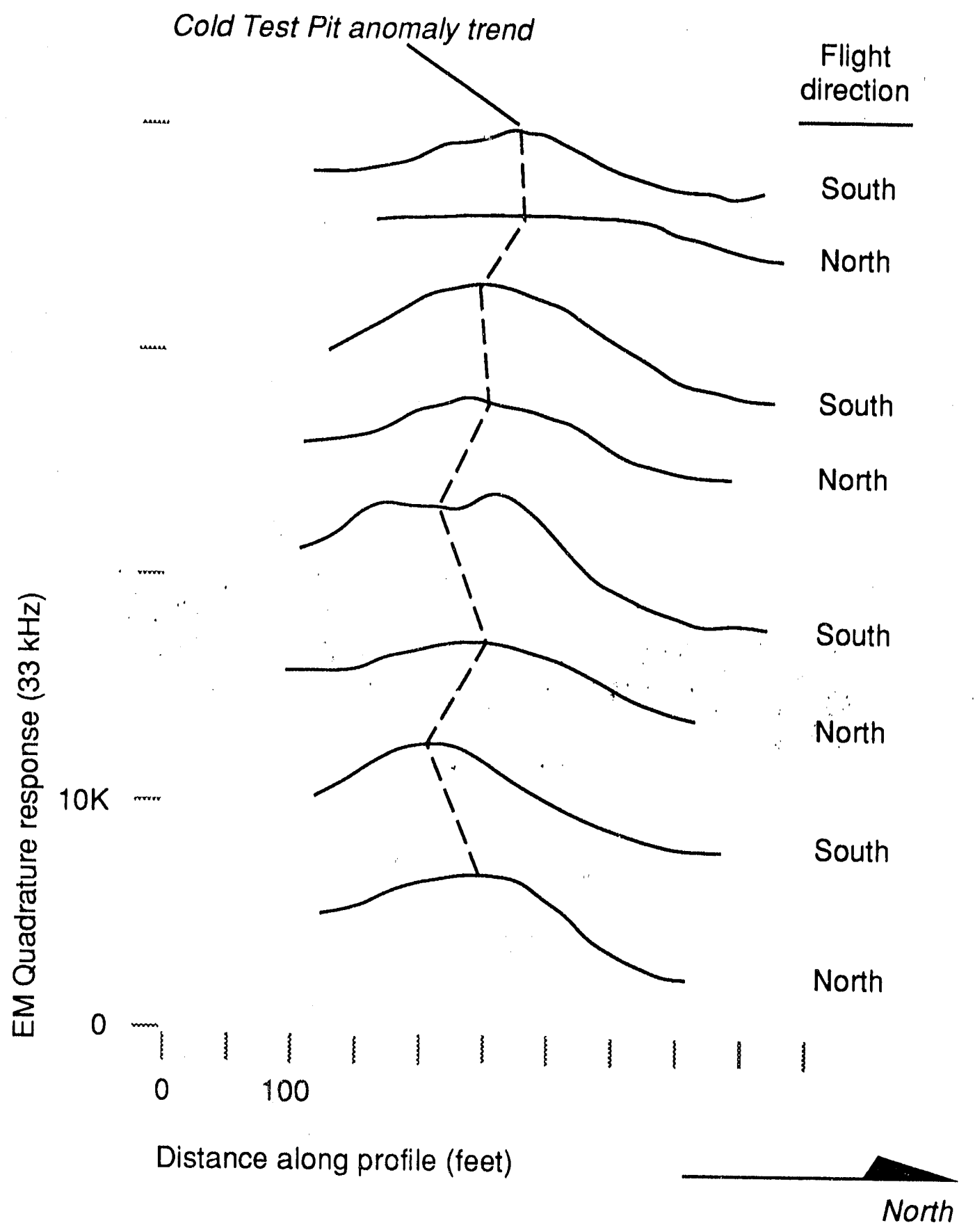

Figure 23. Thirty-three $\mathrm{kHz}$ EM quadrature profiles from the Cold Test Pit showing systematic offset of anomaly peaks. Note the sense of offset in relation to flight direction. Although less clear than for the magnetic data, the lag effect is apparent. 


\subsubsection{Navigation Improvement}

A means to accurately establish data point locations with respect to a standard ground coordinate system is needed. Also needed, but more difficult to achieve, is a means to locate the sensors at all times during the course of operations. For low-level operations, one cannot assume that the sensors track immediately beneath the helicopter.

\subsubsection{Sensor Arrays}

The magnetic sensor array should be expanded so that data can be collected in swaths rather than along single lines. This will improve data spacing in the direction transverse to the flight direction. The use of faster sensors is a simple way to improve point spacing along flight lines. The EM sensor array should be reconsidered and adjusted based on results from the EM data evaluation.

\subsubsection{Regional Geologic/Hydrologic Characterization}

An area should be chosen to perform a test flight that is specifically aimed at investigating shallow subsurface geology, groundwater, and/or groundwater contamination. The large perched groundwater zones near the Test Reactor Area, Big Lost River drainage, and Idaho Chemical Processing Plant at INEL are a possible test site. This is an important potential application for the EBASCO airborne system. 


\section{ADVANTAGES OF SYSTEM INTEGRATION}

The integration of the Martin Marietta and EBASCO systems was discussed repeatedly during the course of planning, executing, and evaluating the INEL demonstration. Some brief comments will be made on this topic.

Data integration should be performed whenever it is possible to more effectively evaluate a site using multiple data sets. This is simply common sense and stems from innumerable reminders that no one data set has all the answers. By using both magnetic and electromagnetic sensors, EBASCO incorporates this principle into their basic system. The use of visual spectrum photography to evaluate several of the thermal anomalies recorded by Martin Marietta is another example of data integration.

Thermal imagery should be used whenever it can be effective in achieving desired characterization objectives. Magnetic and electromagnetic methods should be used likewise. In general, there is little overlap between the types of targets that these two systems sense most effectively. The Martin system is highly sensitive to targets of any size, provided they reside at or near the ground surface. The EBASCO system can sense objects at any depth, provided they are metallic or conductive and sufficiently large. The objectives of the characterization exercise will ultimately determine whether one system, both systems, or neither system is applicable. 


\section{DEPARTMENT OF ENERGY APPLICATIONS}

There are several useful applications for Martin Marietta's airborne thermal imaging system and EBASCO's airborne geophysical system. The main advantage provided by the airborne systems is speed, which translates into an ability to efficiently survey large areas. The applications listed below capitalize on this feature. With minor developments, particularly in navigation, the airborne systems demonstrated at INEL can be effectively used by DOE for these purposes.

\subsection{Ordnance Detection}

Unexploded ordnance hazards are widespread at the INEL and the methods for finding them are labor intensive and prone to uncertainty because $100 \%$ coverage is difficult to obtain. The Martin Marietta thermal system can be an effective tool for performing ordnance searches at the INEL once the navigation shortcomings are corrected. The system's effectiveness at other sites will depend on soil, vegetation, and climate conditions.

\subsection{Reconnalssance Searches for Unknown Waste Sltes}

The EBASCO geophysical system may be the best system available for finding clandestine or abandoned waste burial sites. A capability for rapidly surveying large areas is the most important requirement for this purpose. The Martin Marietta thermal system may be a worthwhile complement to the geophysical system for this application, particularly if outfitted with multispectral cameras that collect visual imagery. The multispectral system would provide capabilities for detecting small isolated objects on the surface, soil disturbances, and chemical spills and could also be used to generate basemaps for future work. Reconnaissance surveys using these systems could identify specific areas for detailed follow up work using ground-based methods. 


\subsection{Geologic/Hydrologic Characterization}

The Environmental Protection Agency has set requirements for characterizing the regional geology and hydrology in the vicinity of waste burial sites. There are similar characterization requirements associated with the building of a waste repository or a nuclear reactor. Geophysical surveys can contribute several types of information to support regional geologic/hydrologic investigations. As with all geophysical work, results are highly site specific. The applications at a given site will depend on the geologic environment. At the INEL, with its unique volcanic stratigraphy, magnetic data can be used to map bedrock depth and to investigate subsurface faults. EM data may be useful for studying groundwater distribution in the shallow basalt section. At other sites, EM data may be used to evaluate subsurface stratigraphy within groundwater aquifers and to locate contaminant plumes.

A regional geologic/hydrologic investigations is intermediate in scale between waste site characterization and mineral, geothermal or petroleum exploration. The EBASCO system is much faster than ground-based data collection, and has improved resolution compared to airborne systems used in resource exploration. This type of system appears to be ideally suited for geologic/hydrologic investigation. 


\section{CONCLUSIONS}

Both Martin Marietta and EBASCO did a commendable job of assembling and deploying their remote sensing systems for the INEL demonstration. The demonstration sites included a variety of characterization problems and were reasonably representative of DOE waste sites nationwide. Data produced by these demonstrations were adequate to establish the basic capabilities and limitations of airborne thermal and geophysical technologies.

These technologies will not be the long sought miracle cure for waste site characterization. In fact, the thermal and airborne systems demonstrated very limited capabilities for meeting the most pressing DOE need - detailed characterization of waste masses at known burial sites. This result was produced by fundamental causes, and it is unlikely that major improvements can be made. However, there are several DOE characterization applications that can be addressed by these technologies. These were clearly demonstrated by the results from the INEL test flights.

\subsection{Martin Marietta Thermal System}

Martin Marietta's thermal system was very successful at detecting objects and soil disturbances located at or very near to the ground surface. Examples of this type of target include ordnance, excavation areas, and chemical spill areas. This type of target produced clear thermal anomalies at certain times of the day, but the same targets were undetectable at other times of the day. Vegetation and ground topography were also found to produce thermal anomalies. These anomalies can be quite similar to anomalies created by ordnance, excavation, or spills and will create problems during interpretation of thermal data. Visual photography may be needed to help make distinctions between anomalies from targets of interest versus anomalies from naturally occurring features of the landscape.

The ability to rapidly interrogate large ground areas is a strong attribute of the thermal imaging technology. Because a wide swath is mapped by each pass of the aircraft, complete ground coverage can be obtained. This is a highly desirable feature for detecting hazardous materials such as ordnance on the ground surface. The Martin Marietta system needs only slight improvements in the navigation system to be a viable technology for making ground searches. The navigation system must be modified so that the thermal imagery can be referenced to a ground coordinate system. Currently, there is no means to follow up thermal anomalies unless a recognizable landmark appears in the image. 
The thermal imagery collected at the INEL buried waste sites showed no indications that buried waste will be detectable. Theoretical calculations suggest that this is a fundamental limitation resulting from limited penetration of solar radiation. These calculations can be improved by determining more realistic thermal properties for the different components of the buried waste detection problem. The depth limit for detectability of objects will be somewhat site dependent, but is unlikely to exceed 1 to $2 \mathrm{ft}$.

Automatic interpretation of the thermal data is possible in cases where anomalies are clearly distinguishable from background clutter. Ordnance produce anomalies with this characteristic when the thermal data are collected at the optimal time of day. The image processor that performs the automated interpretation is fast and consistent but cannot make difficult interpretations in cases where target anomalies and clutter anomalies have similar characteristics.

\subsection{EBASCO Geophysical System}

The EBASCO airborne geophysical system is well suited for locating large, clandestine, or abandoned waste sites within broad search areas. The system does not have the resolution that is achievable by ground-based surveying but is a substantial improvement over airborne systems used in resource exploration industries. The magnetic and EM sensors used for the surveys can detect many types of waste materials (metallic materials create the strongest anomalies) both on the surface and buried. The maximum detection depth depends mainly on the amount of material present but extends to depths that are typical for waste burial. The geophysical system capabilities for detecting large burial areas was demonstrated clearly by data from the INEL fights.

The EBASCO geophysical system may also be applicable to regional geologic and hydrologic investigations. This capability was not emphasized in the selection of INEL test sites or in the data analysis but is an obvious application based on the system's speed and ground coverage capabilities. Fringe data from several of the test sites showed well resolved magnetic anomalies associated with the bedrock basalt. These anomalies can be interpreted to determine qualitative and quantitative properties of the INEL bedrock. The INEL EM data were not fully evaluated, but at other sites EM data have been used successfully to map subsurface stratigraphy, groundwater, and contaminant plumes. At sites where these data can aid the assessment of contaminant distribution and migration, this is a potentially powerful technology.

The EBASCO airborne system has very limited capabilities for making detailed evaluations of buried waste sites. Important objectives such as locating pit boundaries, verifying the presence and location of specific waste objects, or delineating subareas of a burial pit are impossible because of poor data resolution. Locating small isolated objects such as ordnance is impractical because of the difficulties involved in obtaining good ground coverage using magnetic and EM sensors. 
The primary causes for poor resolution are wide data point spacing, high sensor elevations, and imprecise navigation. W/de data point spacing and inaccurate navigation, may be addressed with available technology although at substantial cost. Larger sensor arrays can be flown and sophisticated navigation systems could be designed to locate each of the sensors precisely. However, unless the sensor height limitation can be removed, only modest improvements in the other subsystems are warranted. 


\section{REFERENCES}

Airborne Imaging Detection Survey, Martin Marietta Missile Systems, Final Report for EG\&G Subcontract C91-1332335, 1992.

Anderson, S. R., and B.D. Lewis, Stratigraphy of the Unsaturated Zone at the Radioactive Waste Management Complex, Idaho National Engineering Laboratory, Idaho, USGS Water-Resources Investigations Report 89-4065, 1989.

Locations of Pits, Trenches, and Soil Vault Row's at the SDA, EDF-WAG7-005, November 19, 1991.

Loomis, G., Demonstration of an Airborne System to Characterize Buried Waste, EBASCO Environmental, Draft Final Report for EG\&G Subcontract C91-133274, 1992.

Memorandum from G.K. Miller to W.H. Landman, "Heat Transfer Analysis for Aerial Infrared Scanning Project," EG\&G Idaho, Inc., October 2, 1991.

Yokuda, E., Design and Construction Details of the INEL Simulated TRU Test Pit, EDF-ISV-009, March 2, 1989. 
APPENDIX A
THERMAL MODELLING OF BURIED WASTE

A-1 


\section{APPENDIX A \\ THERMAL MODELLING OF BURIED WASTE}

Thermal analysis was performed by EG\&G Idaho, Inc. personnel to determine the bounding conditions under which deeply buried waste could be detected by the thermal infrared technology proposed by Martin Marietta. These analyses consisted of a simple analytical expression to calculate the depth of the thermal layer as a function of time under diurnal conditions and the use of a simple finite element model to compute surface temperatures given that a buried container was placed underneath the earth's surface at a specified distance. The results of these quick analyses are now presented.

The integral method is a useful tool for calculating the penetration depth of a thermal pulse as a function of time. The integral method for solving heat conduction problems is an approximate analytical technique where the governing partial differential equation is integrated over a phenomenologic distance, $\gamma(t)$, called the thermal layer, to remove the derivative with respect to the spatial variable from the differential equation. The thermal layer is defined as the distance beyond which, for practical purposes, there is no heat flow; hence, the initial temperature distribution remains unaffected beyond $\gamma(t)$. A pictorial representation of the thermal layer as defined is shown in Figure A-1.

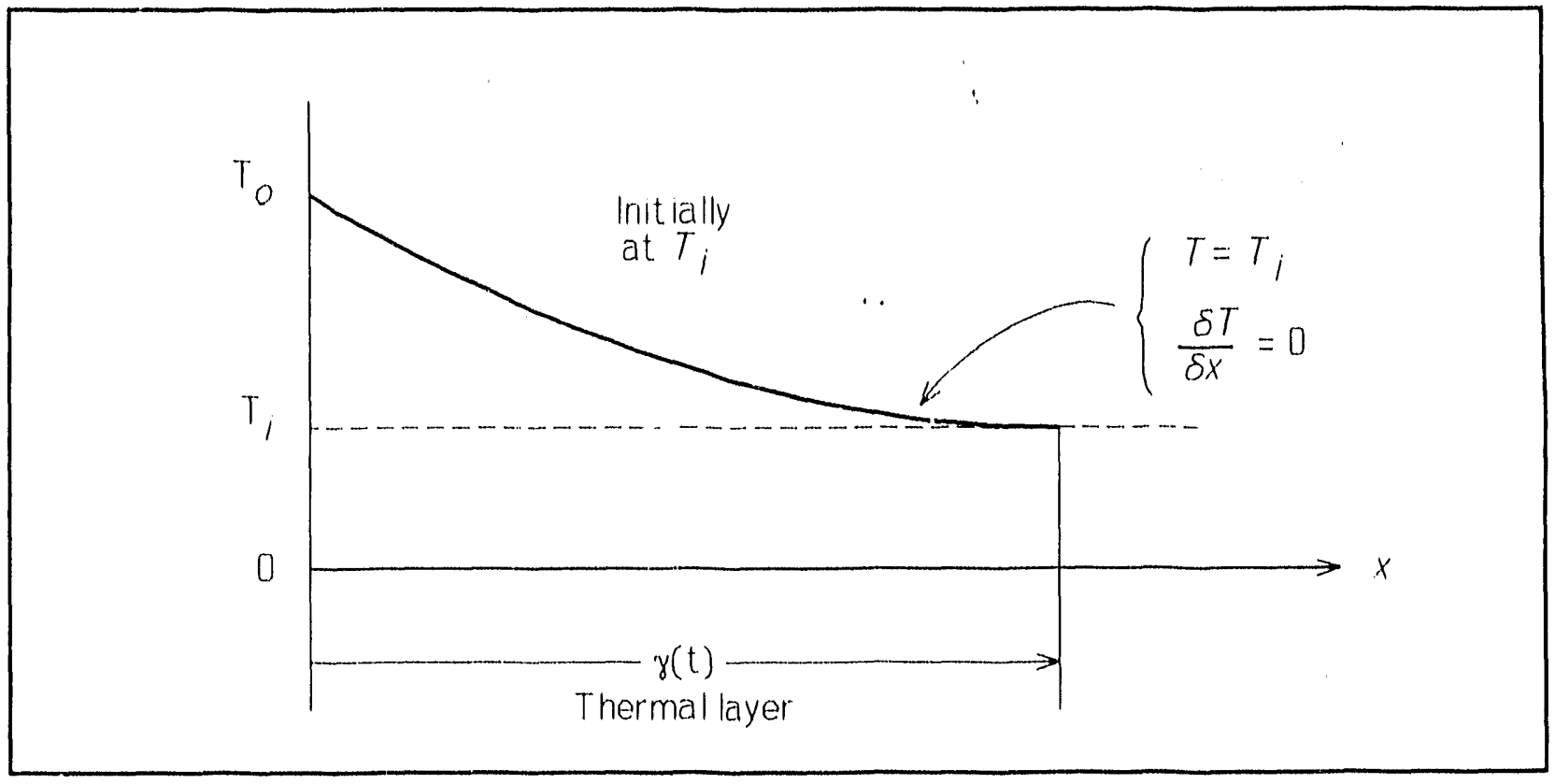

Figure A-1. Thermal layer definition. 
Ozisik (1990) provides several examples of the integral method applied to various thermal problems. An example similar to the buried waste problem is a semi-infinite medium (i.e., the earth) exposed to an external heat source (i.e., the sun). We will assume that the heat flux at the surface of the earth is a constant $C$. This is a more severe case than the half sinusoldal-like thermal loading of the sun on the surface of the earth as the sun rises and sets during a half day. The depth to which the thermal layer penetrates into the earth can be calculated as shown in Equation 1.

$$
\delta=\sqrt{(12 \alpha t)}
$$

\section{where:}

$\delta=$ thermal layer

$\alpha=$ thermal diffusivity

$t=$ time

The thermal diffusivity for soil is a function of composition and moisture content. Kreith (1973) provides a range for soil diffusivity dependent on moisture content. These values vary from $0.01 \mathrm{ft}^{2}$ /hour for $\mathrm{dry}$ soil to $0.03 \mathrm{ft}^{2} /$ hour for wet soil. If these values are used in conjunction with Equation 1, the depth of influence of the thermal layer during any half diurnal cycle (12 hours) is roughly between 1.2 and $2.1 \mathrm{ft}$. Therefore, by this reasoning, the thermal infrared technology employed by Martin Marietta would not be expected to detect buried objects deeper than $2 \mathrm{ft}$ under optimal Idaho National Engineering Laboratory site conditions. This simple analysis is also confirmed by a more rigorous numerical approach described below.

Heat transfer analysis was done by EG\&G Idaho personnel (Miller, 1991) using the ABAQUS finite element program. A block of buried material was placed $3-\mathrm{ft}$ underneath the surface of the earth as shown in Figure A-2. The temperatures within the model were computed every hour for a period of 24 consecutive hours with solar loading during the day and reradiation heat transfer during the night. During the 12 hour day period, the surface of the model was exposed to a sinusoidal heat flux with a peak of $345 \mathrm{Btu} / \mathrm{hour}-\mathrm{ft}^{2}$. At night, the surface was exposed to an effective sky temperature of $410^{\circ} \mathrm{R}$. The emissivity of the soil was assumed to be 1.0 , and the initial iemperature of the model was set to $50^{\circ} \mathrm{F}$. The model is composed of planar heat transfer elements (DC2D4) that are $1 \times 1-\mathrm{ft}$ at the deepest part of the model and 1-ft $\times 3$-in near the surface. 
Re-radiation @ night, Solar Flux In during day
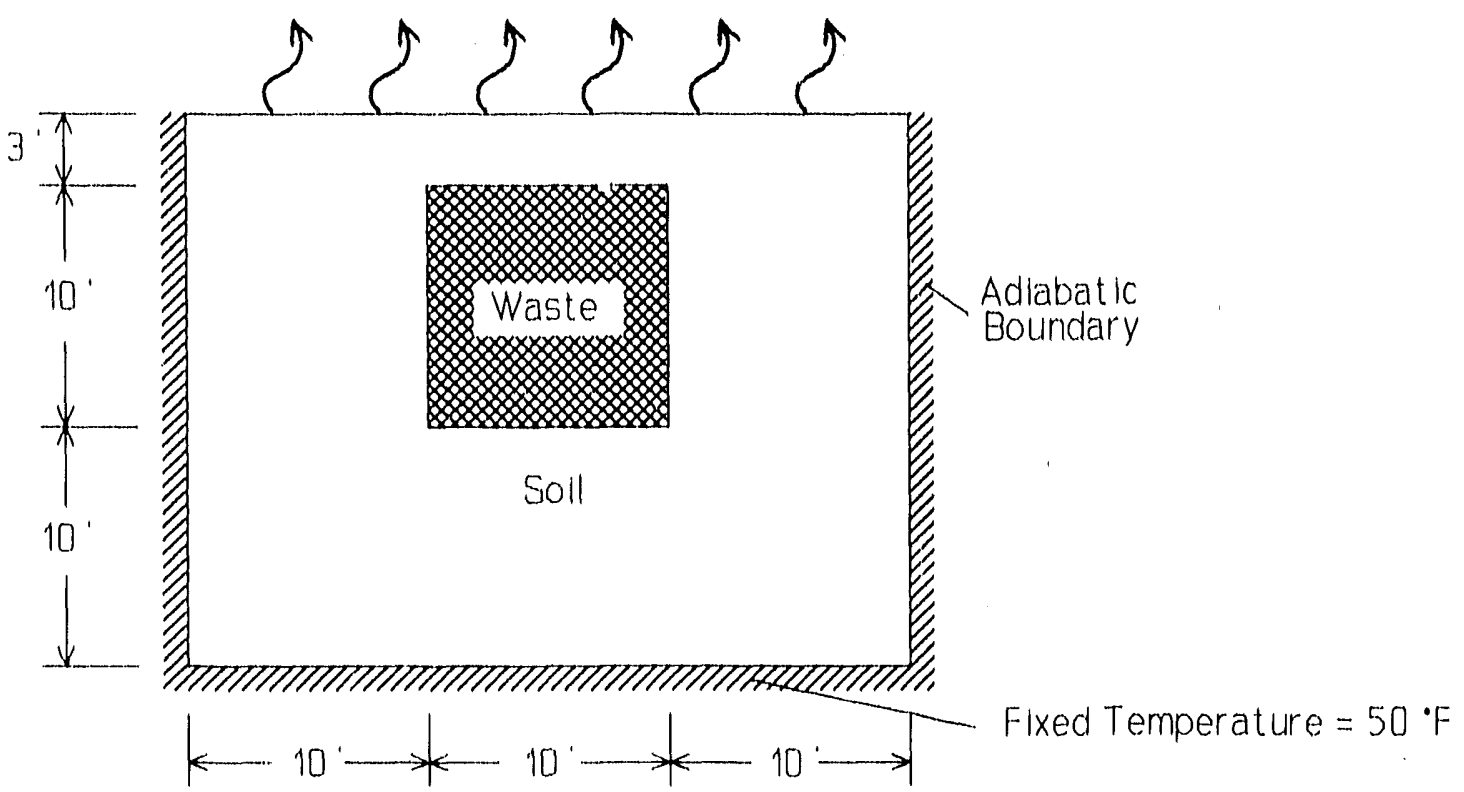

Figure A-2. Schematic of finite element model of buried waste.

The thermal properties used in the analysis for both the soil and the buried object are provided in Table A-1. The analyses were performed with soil conductivities of 0.13 and $0.26 \mathrm{Btu} / \mathrm{hour}-\mathrm{ft}-\mathrm{F}^{\circ}$, respectively. The values used for Soil 2 in Table A-1 roughly correspond to the dry soil diffusivity used in the thermal layer calculation in Equation 1. In both cases, there was insufficient temperature differential for thermal infrared detection from the center surface node to the edge surface node in the model, confirming the above simplified analysis.

Table 1. Soil and buried object properties for finite element analysis.

\begin{tabular}{|c|c|c|c||}
\hline Material & $\begin{array}{c}\text { Conductivity } \\
\left(\text { Btu/hour-ft- } \mathrm{F}^{\circ}\right)\end{array}$ & $\begin{array}{c}\text { Density } \\
\left(\mathrm{lb}_{\mathrm{m}} / \mathrm{ft}^{3}\right)\end{array}$ & $\begin{array}{c}\text { Specific Heat } \\
\left(\mathrm{Btu} / \mathrm{lb}_{\mathrm{m}}-\mathrm{F}^{\circ}\right)\end{array}$ \\
\hline \hline Soil 1 & 0.13 & 70 & 0.4 \\
\hline Soil 2 & 0.26 & 70 & 0.4 \\
\hline Waste & 0.03 & 50 & 0.3 \\
\hline
\end{tabular}




\section{REFERENCES}

Ozisik, M.N., Heat Conduction, John Wiley and Sons, Inc., New York, N.Y., 1990.

Kreith, F., Principles of Heat Transfer, Harper \& Row Publishers, Inc., New York, N.Y., 1973.

Memorandum from G.K. Miller to W.H. Landman, "Heat Transfer Analysis for Aerial Infrared Scanning Project," EG\&G Idaho, Inc., October 2, 1991. 

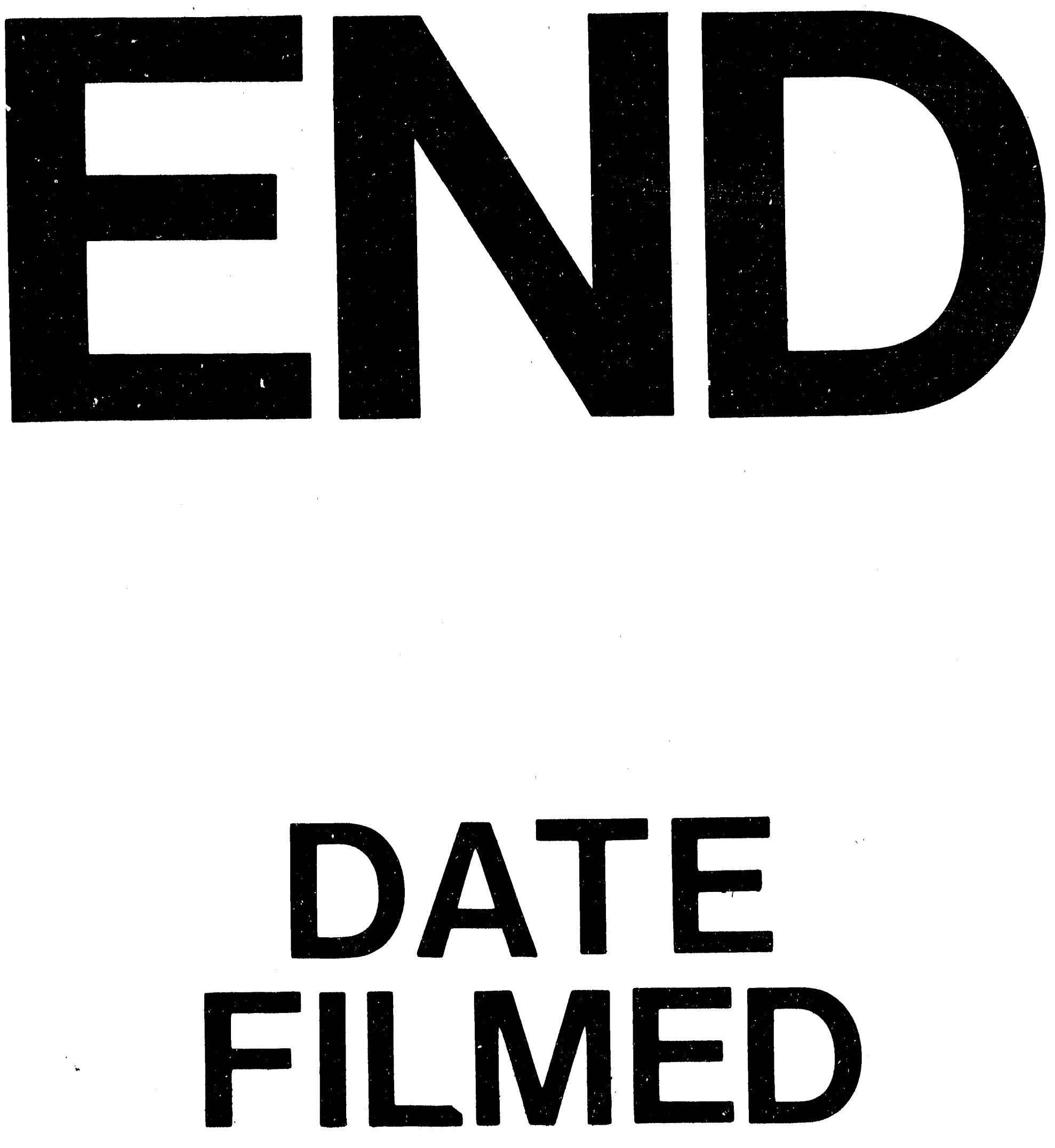

1

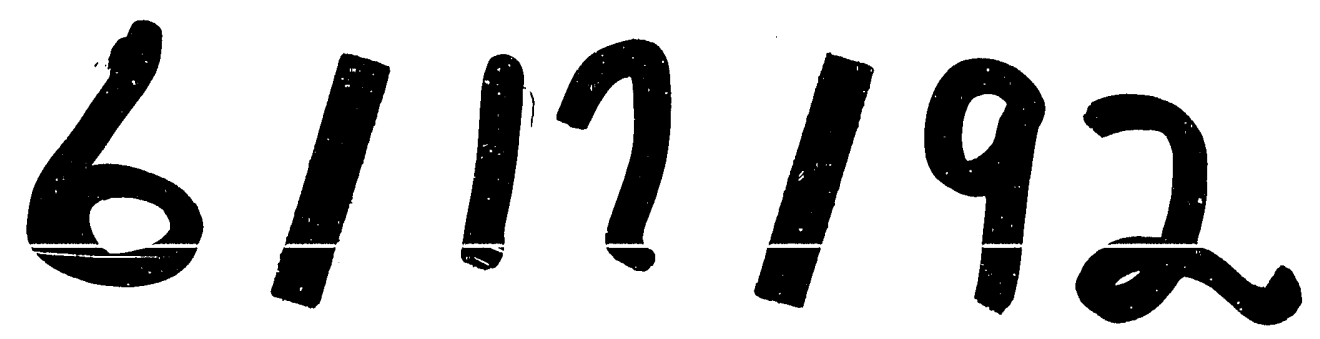


